\title{
Overexpression of SIGRAS40 in Tomato Enhances Tolerance to Abiotic Stresses and Influences Auxin and Gibberellin Signaling
}

\author{
Yudong Liu, Wei Huang, Zhiqiang Xian, Nan Hu, Dongbo Lin, Hua Ren, Jingxuan Chen, \\ Deding Su and Zhengguo $\mathrm{Li}^{*}$
}

School of Life Sciences, Chongqing University, Chongqing, China

OPEN ACCESS

Edited by: Lam-Son Tran

RIKEN, Japan

Reviewed by:

Puneet Paul,

University of Nebraska Lincoln,

United States

Jun Yan,

Purdue University, United States

${ }^{*}$ Correspondence:

Zhengguo $L$

Zhengguoli@cqu.edu.cn

Specialty section: This article was submitted to

Plant Abiotic Stress,

a section of the journal

Frontiers in Plant Science

Received: 25 June 2017 Accepted: 11 September 2017 Published: 26 September 2017

Citation:

Liu Y, Huang W, Xian Z, Hu N, Lin D, Ren H, Chen J, Su D and Li Z (2017)

Overexpression of SIGRAS4O in

Tomato Enhances Tolerance to Abiotic

Stresses and Influences Auxin and

Gibberellin Signaling.

Front. Plant Sci. 8:1659.

doi: $10.3389 /$ fpls.2017.01659
Abiotic stresses are major environmental factors that inhibit plant growth and development impacting crop productivity. GRAS transcription factors play critical and diverse roles in plant development and abiotic stress. In this study, SIGRAS40, a member of the tomato (Solanum lycopersicum) GRAS family, was functionally characterized. In wild-type (WT) tomato, SIGRAS40 was upregulated by abiotic stress induced by treatment with D-mannitol, $\mathrm{NaCl}$, or $\mathrm{H}_{2} \mathrm{O}_{2}$. Transgenic tomato plants overexpressing SIGRAS4O (SIGRAS40-OE) were more tolerant of drought and salt stress than WT. SIGRAS40-OE plants displayed pleiotropic phenotypes reminiscent of those resulting from altered auxin and/or gibberellin signaling. A comparison of WT and S/GRAS4O-OE transcriptomes showed that the expression of a large number of genes involved in hormone signaling and stress responses were modified. Our study of SIGRAS40 protein provides evidence of how another GRAS plays roles in resisting abiotic stress and regulating auxin and gibberellin signaling during vegetative and reproductive growth in tomato.

Keywords: abiotic stresses, auxin, gibberellin, GRAS transcription factor, SIGRAS40, tomato (Solanum lycopersicum)

\section{INTRODUCTION}

Tomato (Solanum lycopersicum) is susceptible to a wide range of environmental stresses. Drought and high salinity are major stress factors leading to detrimental effects, such as inhibition of seed germination and plant growth and decreased fruit productivity. Under drought and salt stress, a series of stress related genes are induced in plants, largely regulated by a range of transcription factors (Hirayama and Shinozaki, 2010). To date, transcription factors from various plant species have been reported to be involved in stress responses (Singh et al., 2002), such as NAC, Dof, ERF, WRKY, bZIP, and MYC/MYB.

Mounting evidence shows that GRAS (named after $\underline{G A I}, \underline{R} G \underline{A}, \underline{S} C R$ ) genes are highly inducible by different abiotic stresses (Czikkel and Maxwell, 2007; Lee et al., 2008). GRAS family proteins are plant-specific transcription factors that play critical roles in plant development and signal transduction pathways, including gametogenesis (Morohashi et al., 2003), phytochrome signaling (Torres-Galea et al., 2006), lateral shoot formation (Li et al., 2003), gibberellin biosynthesis and signaling (Silverstone et al., 1998; Lee et al., 2002), and auxin signaling (Gao et al., 2004; Sanchez et al., 2007). However, some experimental evidence points to certain GRAS proteins having roles 
in resisting biotic or abiotic stress. Tomato SlGRAS6 silenced plants showed increased resistance to disease (Mayrose et al., 2006), overexpression of OsGRAS23 improved drought and oxidative stress tolerance in rice (Kai et al., 2015), and ectopic expression of Populus PeSCL7 gene in Arabidopsis improved drought and salt tolerance (Ma et al., 2010). Overexpression of VaPAT1, a GRAS transcription factor from Vitis amurensis, in transgenic Arabidopsis conferred cold, drought and high salinity tolerance (Yuan et al., 2016). Identifying the roles of other GRAS genes in crops, like tomato, will help elucidate the mechanisms regulating stress tolerance and potentially facilitate the breeding of resistant varieties.

In planta, auxin and gibberellin (GA) are inextricably linked with both developmental processes and abiotic stress responses through the action of GRAS proteins from the SCARECROWlike (SCL) and DELLA groups. AtSCL3 acts as an integrator of DELLAs and SHR-SCR, a complex in which two types of GRAS interact, to mediate GA-promoted cell elongation in the root endodermis (Heo et al., 2011; Zhang Z. L. et al., 2011). The DELLA mutants AtGAI (Peng et al., 1997), AtRGA (Silverstone et al., 1998), and AtRGL1-3 (Lee et al., 2002) all exhibit gibberellin insensitivity. It has been shown that decreased GA content enhances tolerance to drought, whereas increased GA content reduces it (Colebrook et al., 2014). DELLA proteins, the core components of GA signaling, may therefore restrain growth and enhance stress tolerance through a common mechanism (Achard et al., 2008). PrSCL1 (Pinus radiata SCL1) in pine and CsSCL1 (Castanea sativa SCL1) in chestnut regulate adventitious root formation by regulating auxin signaling (Sanchez et al., 2007). The SHR-SCR complex combined with auxin influx carriers LAX3 and AUX1 has a synergetic effect on primary/lateral root development in Arabidopsis (Della et al., 2015). Auxin directly or indirectly modulates the expression of several stress-responsive genes, and several auxin-responsive genes are regulated by abiotic stresses (Jain and Khurana, 2009). Besides, auxin can modulate ROS homeostasis indirectly by affecting the stability of DELLA proteins or directly by inducing ROS detoxification enzymes, suggesting that auxin and GA might cooperate with each other in response to stress conditions (Fu and Harberd, 2003; Paponov et al., 2008).

There are 53 members of the GRAS family in tomato (Huang et al., 2015). In our previous study, we demonstrated that SlGRAS24 participates in a series of developmental processes in tomato by modulating auxin and gibberellin crosstalk (Huang et al., 2017). Here, we found that overexpression of SlGRAS40 (Solyc08g078800) conferred pleiotropic phenotypes and enhanced salt and drought tolerance. By analyzing hormone responsiveness and gene expression we show that altered auxin and gibberellin signaling are likely to be responsible for the defective growth of SIGRAS40-OE.

\section{MATERIALS AND METHODS}

\section{Plant Materials and Growth Conditions}

Tomato plants (Solanum lycopersicum cv. Micro-Tom) were grown in the greenhouse in controlled conditions with $18 \mathrm{~h}$ light $\left(25^{\circ} \mathrm{C}\right) / 6 \mathrm{~h}$ dark $\left(18^{\circ} \mathrm{C}\right)$ cycles and $60 \%$ relative humidity. For gene expression analysis the following samples were collected from at least six plants: roots, stems, and leaves from 1-monthold WT plants; buds, flowers, petals, sepals, and stamens at anthesis; ovaries at $-2,0$, and $4 \mathrm{dpa}$; and fruits at $9 \mathrm{dpa}, 20$ dpa, mature green, breaker, breaker plus 4 day, and breaker plus 7 day stages. Samples from different plants were mixed and immediately frozen in liquid nitrogen.

\section{Plasmid Construction and Genetic Transformation}

The open reading frame of SlGRAS40 without the stop codon was amplified from the full length tomato leaf cDNA and cloned into the expression vector under the CaMV $35 \mathrm{~S}$ promoter. The expression vector was transformed into Agrobacterium tumefaciens strain GV3101, which was used to transform WT tomato plants following standard methods (Fillatti et al., 1987).

\section{Gene Expression Analysis}

Total RNA was extracted using an RNAeasy kit (QIAGEN, Germany) and first-strand cDNA was synthesized with PrimeScript $^{\mathrm{TM}}$ RT reagent Kit with gDNA Eraser (Perfect Real Time) (TAKARA, Japan). Quantitative real-time PCR was performed according to the instructions provided for the Bio-Rad CFX system (Bio-Rad, USA), using SYBR ${ }^{\circledR}$ Premix Ex Taq ${ }^{\mathrm{TM}}$ (Tli RNaseH Plus) (TAKARA, Japan). Relative fold differences were calculated by $2^{-\Delta \Delta \mathrm{Ct}}$ method based on the comparative Ct method. For each sample, three independent biological replicates were used (each with three technical replicates). And all the primers used for qRT-PCR were listed in Supplementary Table S1.

\section{Histological Analysis}

Stems of 1-month-old WT and OE L3 plants were cut and soaked in FAA solution $(50 \%(\mathrm{v} / \mathrm{v})$ ethanol, $5 \%(\mathrm{v} / \mathrm{v})$ glacial acetic acid, $5 \%(\mathrm{v} / \mathrm{v})$ methanal) for $24 \mathrm{~h}$. Samples were dehydrated in an ethanol gradient then embedded in paraffin. Sections were cut and stained with $0.05 \%$ toluidine blue. An Olympus BX-URA2 (Japan) microscopy was used for observations.

\section{Abiotic Stress Treatments}

Leaves of 1-month-old WT plants were sprayed with $200 \mathrm{mM}$ $\mathrm{NaCl}, 100 \mathrm{mM}$ D-mannitol or $100 \mathrm{mM}$ hydrogen peroxide for salt, osmotic, and oxidative treatments, respectively. Control plants were untreated. The leaves were harvested after 1, 3, 6, 12 , and $24 \mathrm{~h}$. For each sample, leaves from six plants were mixed and all treatments were performed three independent times. All samples were frozen in liquid nitrogen and stored at $-80^{\circ} \mathrm{C}$.

For drought tolerance assay, every plant was planted in an independent square basin (same basins were used), each 12 plants of WT and SlGRAS40-OE L2, L3, L4 were placed in a big pot, and watered into the big pot twice a week to make sure the soil water in every basin was uniform, and all the plants were grown under some illumination and temperature conditions. After 1 month, WT and SlGRAS40-OE plants in the big pot were average divided into two groups, one group as control was watered normally, and the other group as drought treatment was deprived of water for up to 17 days. Similarly, the group as salt treatment was watered 
with $200 \mathrm{mM} \mathrm{NaCl}$ every $48 \mathrm{~h}$ ( $200 \mathrm{ml}$ per plant) for up to 23 days. During the treatment process, all the plants in each groups were grown under same illumination and temperature conditions, and three independent treatments were performed. Total chlorophyll content and relative water content (RWC) (Pan et al., 2012) were measured during treatment. After drought or salt treatment, leaf samples at the same developmental stage were harvested, frozen in liquid nitrogen immediately, and stored at $-80^{\circ} \mathrm{C}$.

For osmotic and salt tolerance experiments, seeds of WT and SlGRAS40-OE L2, L3, and L4 were sterilized and sown on $1 / 2 \times$ MS alone or $1 / 2 \times$ MS containing $150 \mathrm{mM} \mathrm{D}$-mannitol or $75 \mathrm{mM}$ $\mathrm{NaCl}$ (Huang et al., 2016). Seeds were incubated in a controlled growth chamber with $18 \mathrm{~h}$ light $\left(25^{\circ} \mathrm{C}\right) / 6 \mathrm{~h}$ dark $\left(18^{\circ} \mathrm{C}\right)$ cycles. The germination rate was counted after 7 days, and the lengths of primary roots and hypocotyls were measured after 2 weeks.

\section{Stoma Morphology and Stomatal Conductance Assay}

An imprint method was used for the assay. Colorless nail polish was applied to the underside of leaves of WT and OE L3 plants. After $5 \mathrm{~min}$, the nail polish was carefully torn off and the imprint viewed with an Olympus BX-URA2 (Japan) microscope. The length and width of stoma were measured with ImageJ software. Stomatal conductance was estimated as the stoma length/width.

\section{Analysis of Antioxidant Enzyme Activities and MDA, Proline, and Soluble Sugar Content}

After drought and salt treatment, leaves at the same developmental stage were harvested for measuring enzyme activities and Malondialdehyde (MDA), proline and soluble sugar content. MDA content was measured according to the method by Heath and Packer (1968), proline content with the method described by Bates et al. (1973), and soluble sugar content by the method described by Fukao et al. (2006). The activity of superoxide dismutase (SOD), catalase (CAT) and peroxidase (POD) were determined according to the methods described by Mittova et al. (2000) and by Morohashi (Mittova et al., 2000; Morohashi, 2002). $\mathrm{H}_{2} \mathrm{O}_{2}$ content and the superoxide anion radical $\left(\mathrm{O}_{2}^{-}\right)$content were determined according to the instructions provided in kits available from Jiancheng Bioengineering Company (Nanjing, China).

\section{Pollen Germination and Pollen Tube Growth Assays}

Pollen from WT and OE L3 plants at flowering time was tested in pollen germination assay. A $30 \mu \mathrm{l}$ drop of medium (20 mM MES buffer, pH6.0, 2\% sucrose, 15\% PEG4000, $1 \mathrm{mM}$ $\mathrm{KNO}_{3}, 3 \mathrm{mM} \mathrm{Ca}\left(\mathrm{NO}_{3}\right)_{2} \cdot 4 \mathrm{H}_{2} \mathrm{O}, 0.8 \mathrm{mM} \mathrm{MgSO} 4 \cdot 7 \mathrm{H}_{2} \mathrm{O}, 1.6 \mathrm{mM}$ $\mathrm{H}_{3} \mathrm{BO}_{3}$ ) was placed on a glass slide in a moist petri dish. A flower undergoing anthesis was shaken to let pollen fall onto the medium. The petri dish was sealed and kept in the dark at $25^{\circ} \mathrm{C}$ for 5-6 h. Observations were made with an Olympus BX-URA2 microscope (Japan). For pollen tube growth assays, 1-dpa ovaries were soaked in buffer (95\% ethanol-glacial acetic acid, v/v, 3:1) for $24 \mathrm{~h}$, then transferred to $8 \mathrm{M} \mathrm{NaOH}$ for 2 days. Samples were washed in water three times, and stained with $0.05 \%$ aniline blue for $4 \mathrm{~h}$ in the dark. An Olympus BX-URA2 microscope (Japan) with ultraviolet light excitation was used for observations of pollen tubes.

\section{Hormone Treatment for Plant Development Analysis}

Ten-day-old WT and SlGRAS40-OE L3 plants were sprayed with $20 \mu \mathrm{M} \mathrm{GA} 3$ every 3 days for 4 weeks. Control plants were sprayed with water. Plant height was measured every week and flowering time was recorded. The auxin dose-response experiment was performed with 8-mm long hypocotyl segments excised just below the cotyledon nodes from 7-day-old WT and SlGRAS40-OE L3 seedlings. Hypocotyl segments were floated onto sucrose/MES buffer [1\% (w/v) sucrose, $5 \mathrm{mM} \mathrm{MES/KOH,}$ pH6.0] and pre-incubated for 1-2 h. The hypocotyl segments were then randomly distributed to fresh buffer solutions with or without NAA and measured after $23 \mathrm{~h}$ of incubation with gentle agitation at room temperature (Wang et al., 2005).

The seeds of WT and SlGRAS40-OE L2 and L3 were sterilized and soaked in sterilized water with gentle agitation at room temperature, then seeds were transferred to $1 / 2 \times$ MS medium with $1 \mu \mathrm{M}$ IAA and/or $50 \mu \mathrm{M} \mathrm{GA} 3$, or on $1 / 2 \times$ MS medium without hormone for controls. The seedlings were grown in a growth chamber with controlled conditions, $18 \mathrm{~h}$ light $\left(25^{\circ} \mathrm{C}\right) / 6$ $\mathrm{h}$ dark $\left(18^{\circ} \mathrm{C}\right)$ cycles. After 15 days, the number of lateral roots, and the lengths of primary roots and hypocotyls were measured. Every treatment was done on at least 10 plants or 30 seeds and all the treatments were performed three independent times.

\section{Hormone Treatment for Gene Expression Analysis}

Fifteen-day-old WT seedlings were soaked in liquid $1 / 2 \times \mathrm{MS}$ medium containing $20 \mu \mathrm{M}$ IAA or $20 \mu \mathrm{M} \mathrm{GA}_{3}$ for $0,1,3,6,12$, or $24 \mathrm{~h}$, then whole seedlings were frozen in liquid nitrogen and stored at $-80^{\circ} \mathrm{C}$.

Fifteen-day-old WT and OE L3 seedlings were soaked in liquid $1 / 2 \times$ MS medium containing $20 \mu \mathrm{M}$ IAA or $20 \mu \mathrm{M} \mathrm{GA} 3$ for $3 \mathrm{~h}$, then whole seedlings were frozen in liquid nitrogen and stored at $-80^{\circ} \mathrm{C}$. Seedlings were soaked in liquid $1 / 2 \times$ MS medium without hormones as controls. Each treatment was performed three independent times.

$\mathrm{GA}_{3}$ (2000 ng per ovary, Sigma, USA) or 2,4-D (200 ng per ovary, Sigma, USA) was applied to emasculated ovaries on the day equivalent to anthesis ( $0 \mathrm{dpa}$ ) in $10 \mu \mathrm{l}$ of $5 \%$ ethanol and $0.1 \%$ Tween 80 (Sigma, USA) solution. Ovaries were treated with the same volume of solution without hormones as control. Eight ovaries (from four plants) were used per treatment, and each treatment was performed three independent times. The samples were frozen in liquid nitrogen and stored at $-80^{\circ} \mathrm{C}$ before RNA extraction and gene expression analysis. Flower emasculation was carried out 2 days before anthesis $(-2 \mathrm{dpa})$ to prevent self-pollination (Serrani et al., 2007a).

\section{RNA Sequencing}

Total RNA (RNeasy Plant Mini Kit, Qiagen, USA) was extracted from shoot apical meristems from 1-month-old 
WT and SlGRAS40-OE L3 plants, two individuals per sample. A cDNA library was constructed for sequencing on the IlluminaHiSeq2000 $0^{\mathrm{TM}}$ system (BGI Inc.). Bowtie2 was used to map clean reads to the reference genome of $S$. lycopersicum in the Tomato Sol Genomic Network database (http://solgenomics.net/), and the homogenized data used to calculate gene expression levels with RSEM. Differentially expressed genes (DEGs) were detected with NOIseq with the following parameters: fold change $\geq 2.00$ and probability $\geq$ 0.8 . Gene ontology (GO) functional enrichment and Kyoto Encyclopedia of Genes and Genomes (KEGG) pathway analysis were performed between WT and SIGRAS40-OE samples.

\section{Statistical Analysis}

All the experiments included three independent repeats, and significant differences were determined by the Student's $t$-test at significance levels of $P<0.05\left(^{*}\right)$ and $P<0.01\left(^{* *}\right)$.

\section{RESULTS}

\section{Phenotypic Characterization of Transgenic Plants Overexpressing SIGRAS40}

We generated transgenic tomato plants with the SlGRAS40 cDNA under the control of the CaMV 35S promoter by Agrobacterium tumefaciens-mediated transformation. Three independent lines L2, L3, L4 were obtained overexpressing the gene 8.6-fold, 30.5-fold, and 11.7-fold, respectively (Figures 1A,C). SlGRAS40 overexpressing plants exhibited pleiotropic phenotypes including dwarfism (Figure 1B), delayed flowering time, decreased fruit-set ratio, and arrested fruit and seed development. More details of the phenotypes are shown in Supplementary Table S2. SlGRAS40 was expressed in all WT tissues tested, and expressed at much higher levels in leaves and flowers undergoing anthesis compared to roots (Figure 1D).

The sixth node stems of 1-month-old WT and SlGRAS40-OE L3 plants were used for histological analysis (Figure 1E). In

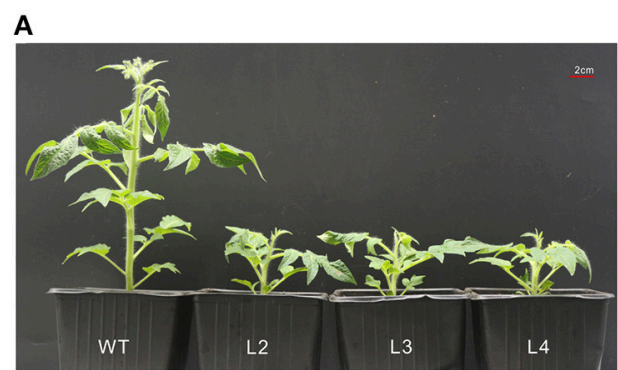

B

C

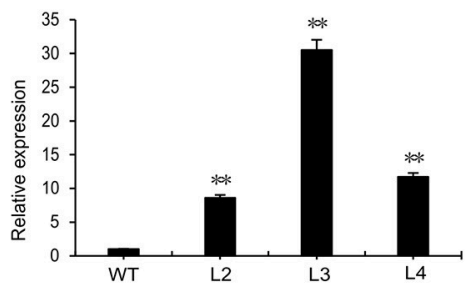

E
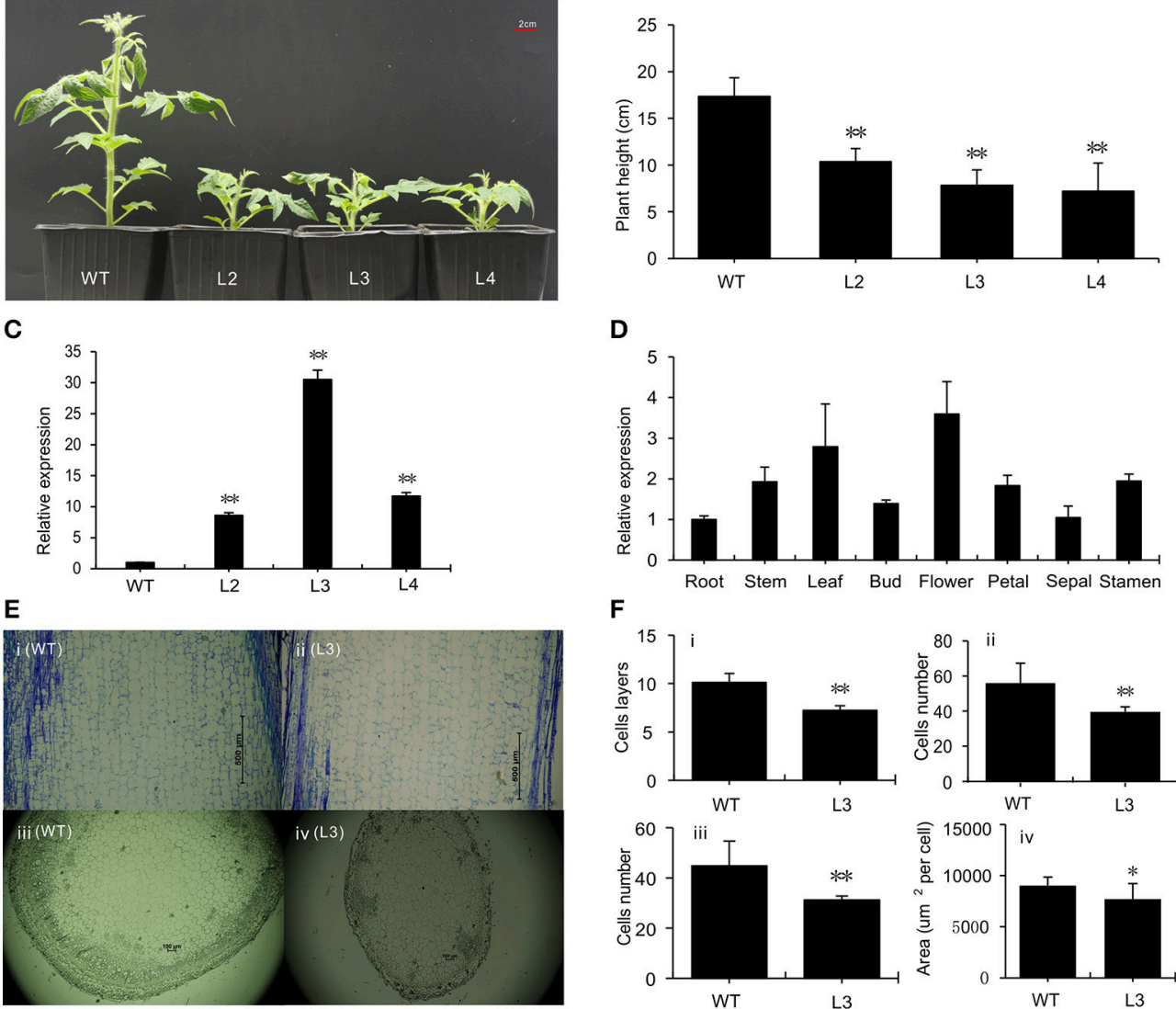

D

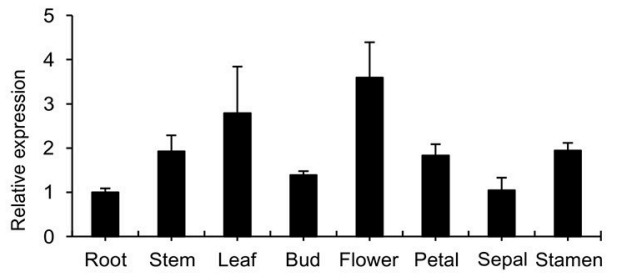

$\mathbf{F}$
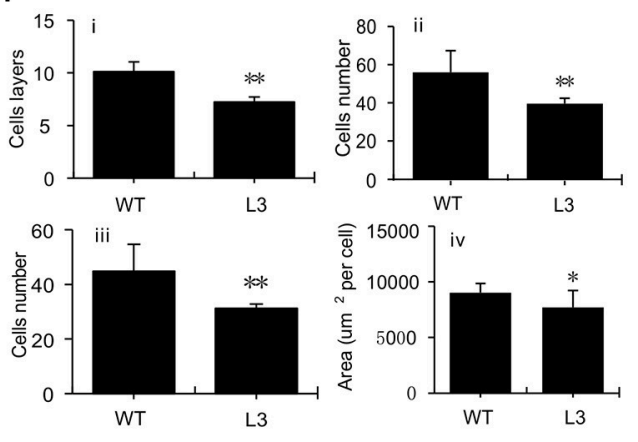

FIGURE 1 | Phenotypic characterization of wild-type and transgenic plants. (A) One-month-old plants of WT and S/GRAS40-overexpressing lines. L2, L3, L4, three independent SIGRAS40-overexpressing lines. (B) Height of plants shown in (A). Error bars show the standard error between three biological replicates $(n=3)$ with more than 10 plants for each replicate performed. (C) Expression levels of SIGRAS40 in plants of WT and SIGRAS40-OE lines. Expression data were normalized with SIGRAS40 expression in WT as 1. Error bars show the standard error between three biological replicates $(n=3)$. (D) Tissue profiling analysis of SIGRAS40 in different organs of wild-type tomato. Expression data were normalized with SIGRAS40 expression in root set as 1. (E) Histological analysis of 1-month-old stems from WT (i, iii) and SIGRAS4O-OE L3 (ii, iv) shown in longitudinal section (i, ii) and transverse section (iii, iv). (F) Analysis of histological data from (E). (i) and (ii) are data from longitudinal sections; (iii) and (iv) are data from transverse sections. All data are measurements under $40 \times$ microscopic field. Asterisks indicate significant differences using Student's $t$-test ${ }^{\star} P<0.05,{ }^{\star \star} P<0.01$ ). 
longitudinal sections, there were fewer cell layers and fewer cells in OE plants compared with WT, and the average area of OE cells was bigger than WT cells. In transverse section, OE plants had fewer and smaller cells compared to WT (Figure 1F). The difference in cellular makeup explains why SIGRAS40-OE stems are thinner and shorter than WT stems.

\section{Overexpression of SIGRAS40 Enhances Tolerance to Drought and Salt Stress}

WT plants were treated with $\mathrm{D}$-mannitol, $\mathrm{NaCl}$, or $\mathrm{H}_{2} \mathrm{O}_{2}$ to produce the effects of osmotic, saline or oxidative stress, respectively. SlGRAS40 was up-regulated in response to $100 \mathrm{mM}$ D-mannitol and to $100 \mathrm{mM} \mathrm{H}_{2} \mathrm{O}_{2}$, but in response to 200 $\mathrm{mM} \mathrm{NaCl} \mathrm{SlGRAS40}$ was first down-regulated then up-regulated (Figure 2A). SlGRAS40 may therefore be involved in abiotic and oxidative stress responses in tomato.

To evaluate the role of SlGRAS40 in tolerance to drought and salt, SlGRAS40-OE L2, L3, L4 and WT plants were deprived of water for up to 17 days as a drought stress treatment, or watered with $200 \mathrm{mM} \mathrm{NaCl}$ solution every $48 \mathrm{~h}$ for up to 23 days as a salt stress treatment. Under saline or drought stresses, all OE plants grew better than WT (Figure 2B). Under drought stress, desiccation symptoms, such as wilting of lower leaves were readily observed in WT, whereas OE plants exhibited only slight damage (Figure 2C). Under salt stress, WT plants mostly exhibited increased chlorosis and necrosis after 23 days, but there was no obvious damage in OE plants (Figure 2C). Relative water content (RWC) and total chlorophyll content both declined in WT and OE plants during stress treatments, but levels were much higher in OE than in WT (Figures 2D-G). After drought stress, the stomatal conductance of WT had decreased (Figures 3A,B), indicating that stomatal pores were wider open. The effect would be to increase transpiration leading to lower RWC (Figure 2D). On the contrary, after drought stress the stomatal conductance of SlGRAS40-OE L3 leaves increased and was significantly higher than that of WT leaves (Figure 3B). This indicated that under drought stress the stomatal pores of SlGRAS40-OE leaves were narrowed so more water was retained (Figure 2D).

\section{Antioxidant Status of SIGRAS40-OE Plants under Drought and Salt Stress}

Abiotic stresses induce oxidative stress in plants which leads to the accumulation of abundant ROS. We investigated whether $\mathrm{H}_{2} \mathrm{O}_{2}$ and $\mathrm{O}_{2}^{-}$accumulate in WT and OE L2, L3, L4 plants after drought or salt treatment. Results show that drought and salt stress induced more $\mathrm{H}_{2} \mathrm{O}_{2}$ and $\mathrm{O}_{2}^{-}$to accumulate in WT plants, but there was no obvious change in OE plants (Figure 4A). MDA, proline, and soluble sugar contents were measured in treated and control plants (Figure 4A), as accumulation of these compounds is characteristic of physiological stress. MDA content increased significantly in WT plants under drought and salt stress, and slightly increased in OE plants but not as much as in WT. The proline content of both WT and OE plants increased after drought and salt stress, but more proline accumulated in OE plants under salt stress. There was an obvious decrease in soluble sugar in WT plants after salt treatment, whereas OE plants accumulated more soluble sugar after drought and salt stress.

The activities of three antioxidant enzymes, POD, SOD, and CAT, were measured in this study. There were no significant differences in either POD or SOD activities in WT and OE plants under normal conditions. Under drought stress both POD and SOD activities were up-regulated in OE plants, but not in WT plants. By comparison, these two activities were significantly upregulated in WT plants after salt treatment (Figure 4A). Saltstressed OE had lower levels of POD and SOD than WT in the same conditions. CAT activity was higher in OE than in WT plants under both control and drought stress conditions, but after salt treatment the CAT activity was up-regulated in WT but not in OE (Figure 4A). These data indicate that overexpression of SlGRAS40 can enhance ROS scavenging ability under salt and drought stress.

\section{Expression Analysis of Stress-Related Genes in SIGRAS40-OE and WT Plants under Drought and Salt Stress}

To investigate the molecular mechanisms underlying SlGRAS40enhanced tolerance to drought and salt stress, expression of plant stress response biomarkers was checked by quantitative reverse transcription (qRT)-PCR (Figure 4B). The transcript levels of several genes involved in ROS generation and scavenging, including ascorbate peroxidase (APX), CAT, SOD, $P O D$, lipoxygenase $(L O X)$, and glutathione S-transferase (GST), were measured in WT and transgenic plants under both normal and stress conditions. The transcript abundance of all these genes, except SlGST, decreased in WT and OE plants after stress treatment, but the expression levels in OE plants were higher than those in WT in both control and stress conditions (Figure 4B). SlGST was up-regulated in WT after drought or salt stress, and up-regulated in OE plants after salt stress, but after drought stress SlGST expression level was lower in OE than in WT. A key proline synthetase gene SIP5CS was up-regulated after stress treatment in WT plants, while OE plants had higher levels than WT under control and salt conditions (Figure 4B). An ascorbic acid synthetase (SlGME2), an ethylene-responsive LEA protein (SlER5), an ethylene-responsive factor (SlERF1) and a heat shock protein ( $S l H s p 90-1)$ all have higher expression levels in OE plants than in WT after drought and salt stress (Figure 4B). These results indicated that SlGRAS40 may be involved in stress signaling pathways by modulating these genes in tomato.

\section{Overexpression of SIGRAS40 Improves Seed Germination Rate under Osmotic and Salt Stress}

The osmotic and salt tolerance of seed germination was tested on seeds harvested from WT and OE L2, L3, L4 plants (Figures 5A,B). The germination rate of both genotypes declined under $150 \mathrm{mM}$ D-mannitol and $75 \mathrm{mM} \mathrm{NaCl}$, respectively (Figure 5C). The germination rate of $\mathrm{OE}$ seeds was significantly higher than that of WT seeds under either stress condition, on 

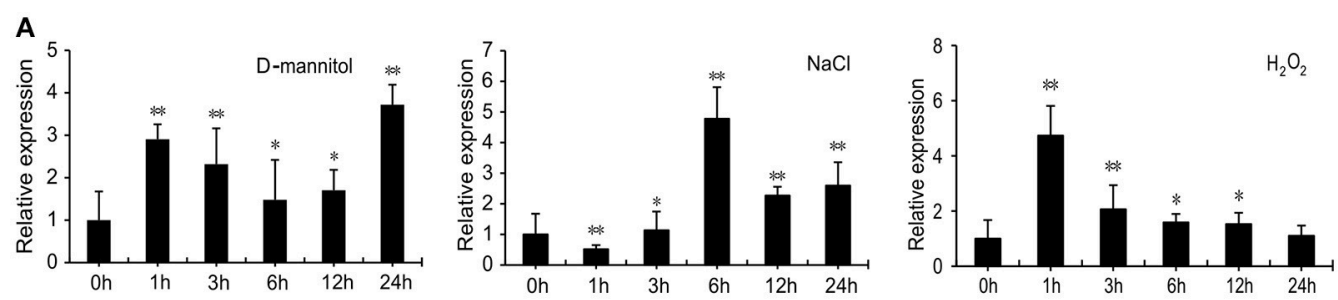

B

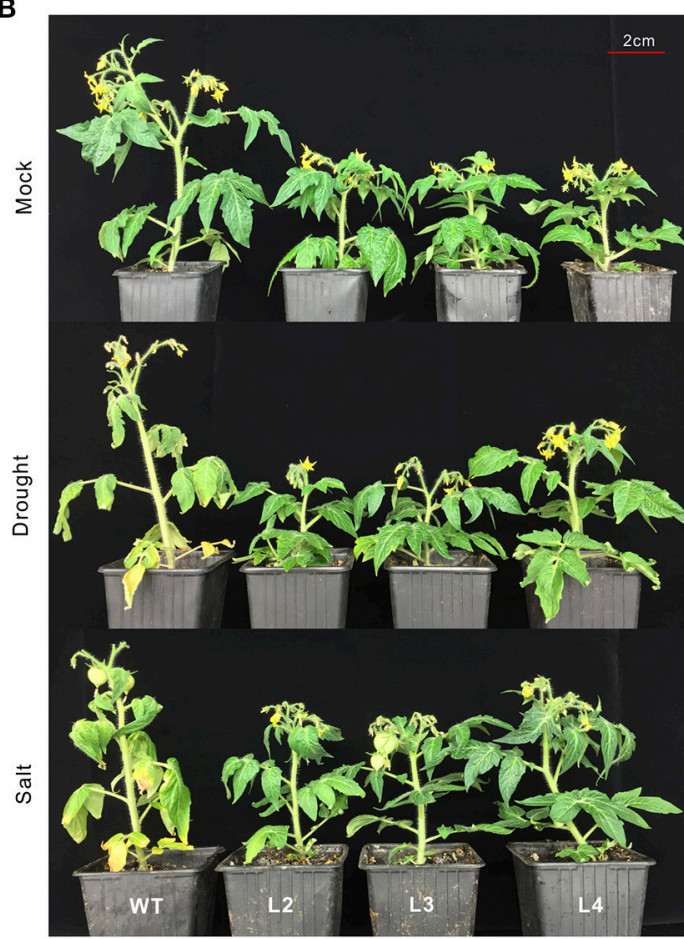

D

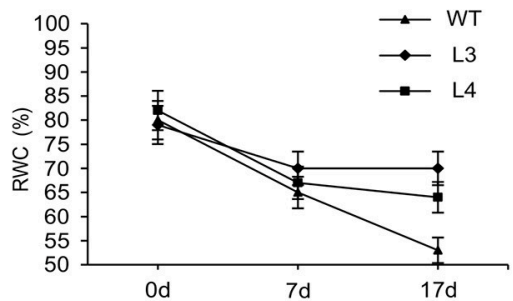

F

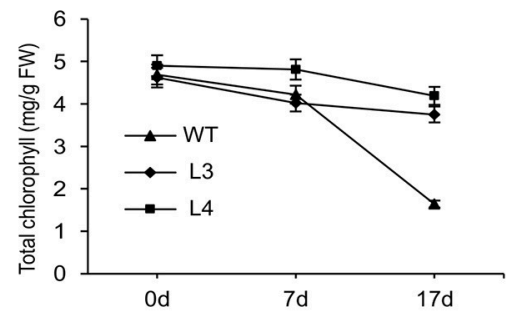

C

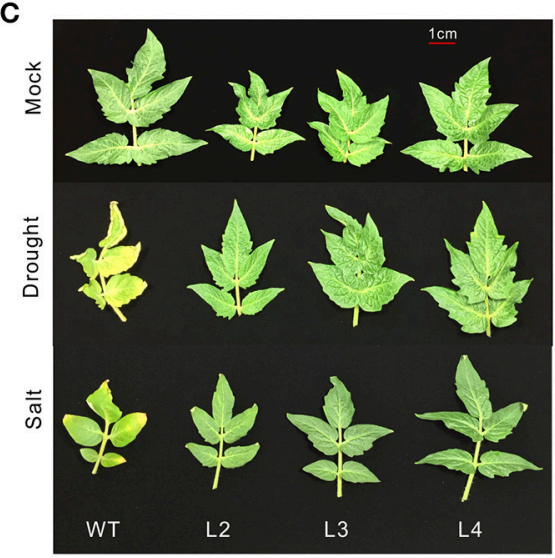

E

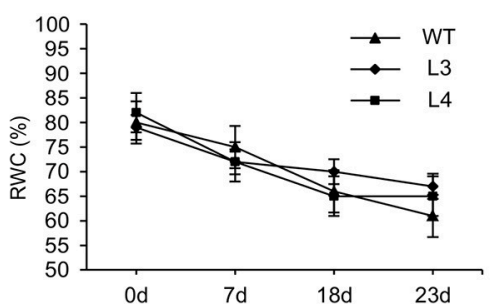

G

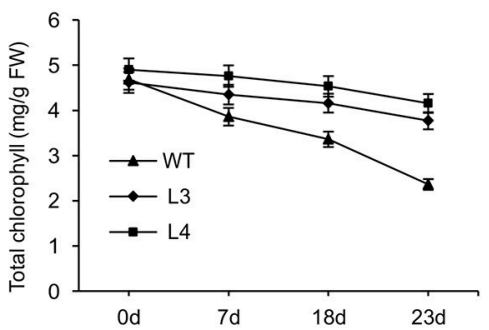

FIGURE 2 | Overexpression of SIGRAS40 enhances tolerance to drought and salt stress. (A) Quantitative RT-PCR analysis of SIGRAS4O mRNA from leaves of 1-month-old WT plants sprayed with $100 \mathrm{mM} \mathrm{D-mannitol,} 200 \mathrm{mM} \mathrm{NaCl}$, or $100 \mathrm{mM} \mathrm{H}_{2} \mathrm{O}_{2}$. Expression data was normalized with expression of S/GRAS40 in treated plants at $0 \mathrm{~h}$ set as 1. Asterisks indicate significant differences using Student's $t$-test $\left({ }^{\star} P<0.05\right.$, $\left.{ }^{\star *} P<0.01\right)$. (B) Photographs of representative plants after 17 days of drought treatment or 23 days of salt treatment compared to control plants. (C) Phenotypes of the fifth leaves of plants shown in (B). RWC (D,E) and total chlorophyll content $(\mathbf{F}, \mathbf{G})$ were measured after drought $(\mathbf{D}, \mathbf{F})$ and salt $\mathbf{( E , G ) ~ s t r e s s ~ t r e a t m e n t . ~ E r r o r ~ b a r s ~ s h o w ~ t h e ~ s t a n d a r d ~ e r r o r ~ o f ~ d a t a ~ f r o m ~ t h r e e ~ r e p l i c a t e s . ~}$ 

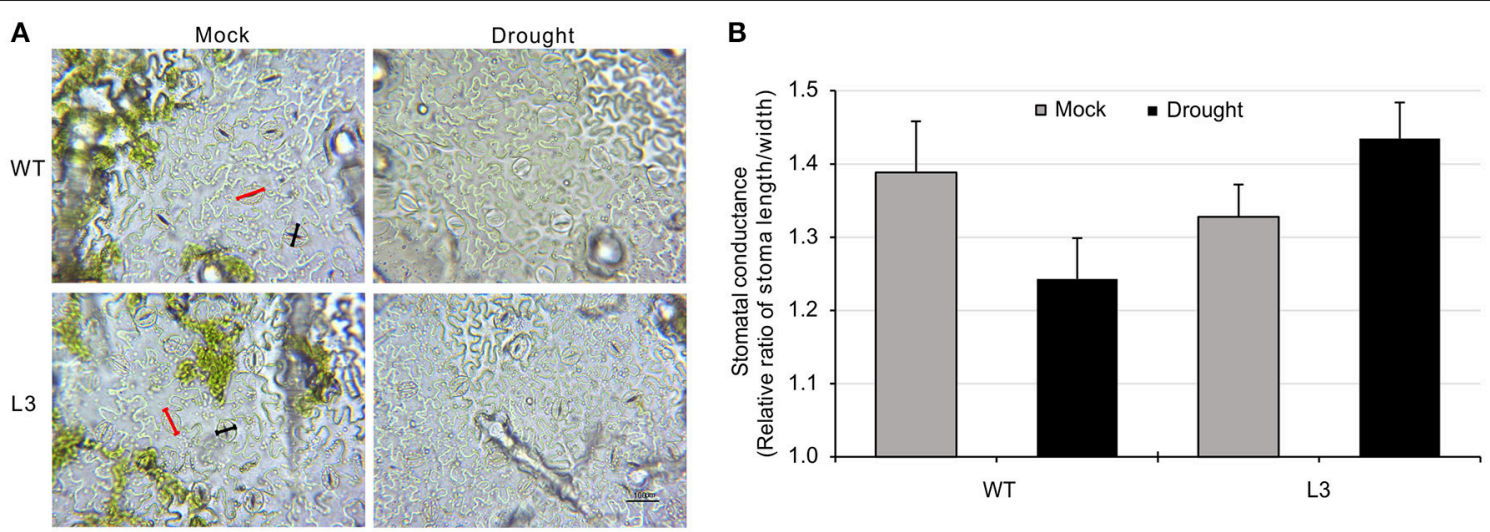

FIGURE 3 | Overexpression of SIGRAS40 reduces stoma opening under drought stress. (A) Stoma morphology of WT and SIGRAS40-OE L3 leaves under mock and drought conditions. Red indicates pore length, black indicates pore width. (B) Stomatal conductance of WT and SIGRAS4O-OE L3 leaves under mock and drought conditions. Stomatal conductance $=$ pore length/pore width. Error bars show the standard error between three biological replicates $(n=3)$ with more than five leaves per replicate.

average 76.3 vs. $66.7 \%$ after osmotic treatment and 76 vs. $58 \%$ after salt treatment.

Root elongation was significantly delayed under osmotic and salt stress, but OE root length was longer than WT root length under the corresponding stress treatments (Figure 5D). OE hypocotyls were longer than WT after D-mannitol treatment, but shorter than WT under salt stress (Figure 5E). These results showed that SlGRAS40-OE seeds and seedlings resist drought and salt stress better than WT.

\section{Overexpression of SIGRAS40 Alters Responsiveness to IAA and $\mathrm{GA}_{3}$}

The expression level of SlGRAS40 fell after IAA and $\mathrm{GA}_{3}$ treatment in WT (Figure 6A), indicating that SlGRAS40 is responsive to auxin and gibberellin. To explore the relationship between SlGRAS40 and the two phytohormones, WT and OE L3 seedlings were treated with $1 \mu \mathrm{M}$ IAA or $50 \mu \mathrm{M} \mathrm{GA}_{3}$. SlGRAS40OE seedlings had fewer lateral roots and longer primary roots than WT after IAA treatment (data of L3 in Figure 6B, data of L2 in Supplementary Figure S1), indicating that overexpression of SlGRAS40 weakens the responsiveness to IAA. The auxin sensitivity of SlGRAS40-OE plants was explored by determining the auxin dose-response of elongation of hypocotyl segments. Maximum hypocotyl segment elongation was obtained with $10^{-5}$ M NAA both in OE L3 and WT, but the hypocotyl elongation of OE L3 was less than WT at each auxin concentration (Figure 6I). These data indicated that overexpression of SlGRAS40 reduced hypocotyl auxin responsiveness.

In response to $50 \mu \mathrm{M} \mathrm{GA}_{3}$, hypocotyls of both WT and OE L3 seedlings elongated more than controls without $\mathrm{GA}_{3}$. Outgrowth of the first true leaves from the shoot apex was suppressed in OE L3 seedlings compared with WT, and WT seedlings had more lateral roots than OE L3 seedlings (Figure 6B, and data of L2 in Supplementary Figure S1). The dwarf phenotype and delayed flowering time could be rescued to a level similar to WT by spraying with $20 \mu \mathrm{M} \mathrm{GA} 3$ (Figure 6F). These results showed that overexpression of SIGRAS40 induced GA-deficient phenotypes, so SlGRAS40 may be involved in GA biosynthesis or signaling.

\section{Overexpression of SIGRAS40 Influences Fruit Size and Disturbs Fertilization}

In plants overexpressing SlGRAS40, the fruit size was smaller than WT (Figures 7A,D). The normal fertilization process was also disrupted as the fruit set ratio and the number of seeds were significantly lower than in WT, and fresh weight and fruit production also decreased (Figures 7B,E-H). Studying the expression pattern at different stages of WT ovary and fruit development showed that SIGRAS40 was up-regulated by pollination and fertilization, but has relatively low expression levels in fruits (Figure 7C). Final fruit size is controlled by genes related to cell division and cell expansion (Gillaspy et al., 1993), so we checked the expression levels of such genes in WT and OE L3 fruits harvested at 4, 9, and 20 dpa (Figure 7I). Genes related to cell division SlCyCB1.1 (Solyc06g073610) and SlCyCD3.1 (Solyc02g092980) were significantly down-regulated in $4 \mathrm{dpa}, 9 \mathrm{dpa}$ and $20 \mathrm{dpa} \mathrm{OE}$ fruits compared with WT. The gene SlEXP18 (Solyc06g076220), which regulates cell expansion, was significantly down-regulated in $20 \mathrm{dpa}$ OE fruits, and the gene SlPec (Solyc06g083580) was remarkably down-regulated in 4 dpa and 9 dpa OE fruit (Figure 7I).

As the fruit-set ratio and seed number decreased, a crossfertilization assay was performed to explore whether the stamens or pistils in SlGRAS40-OE plants were defective (Figure 8A). The fruit-set ratio was 95, 30, and 35\% for WT, OE-L3 and OE-L4 self-pollination, respectively, and when WT was the female recipient the fruit-set ratio of WT fell to 77 and $72 \%$ with OE L3 and OE L4 pollen, respectively, while the seed number, fruit size and fresh weight all decreased. When $\mathrm{OE}$ L3 and OE L4 (o) stigmas received WT pollen $\left(\sigma^{7}\right)$, the fruitset ratio increased to 60 and 61\%, respectively, while the seed number, fruit size and fresh weight all increased slightly 


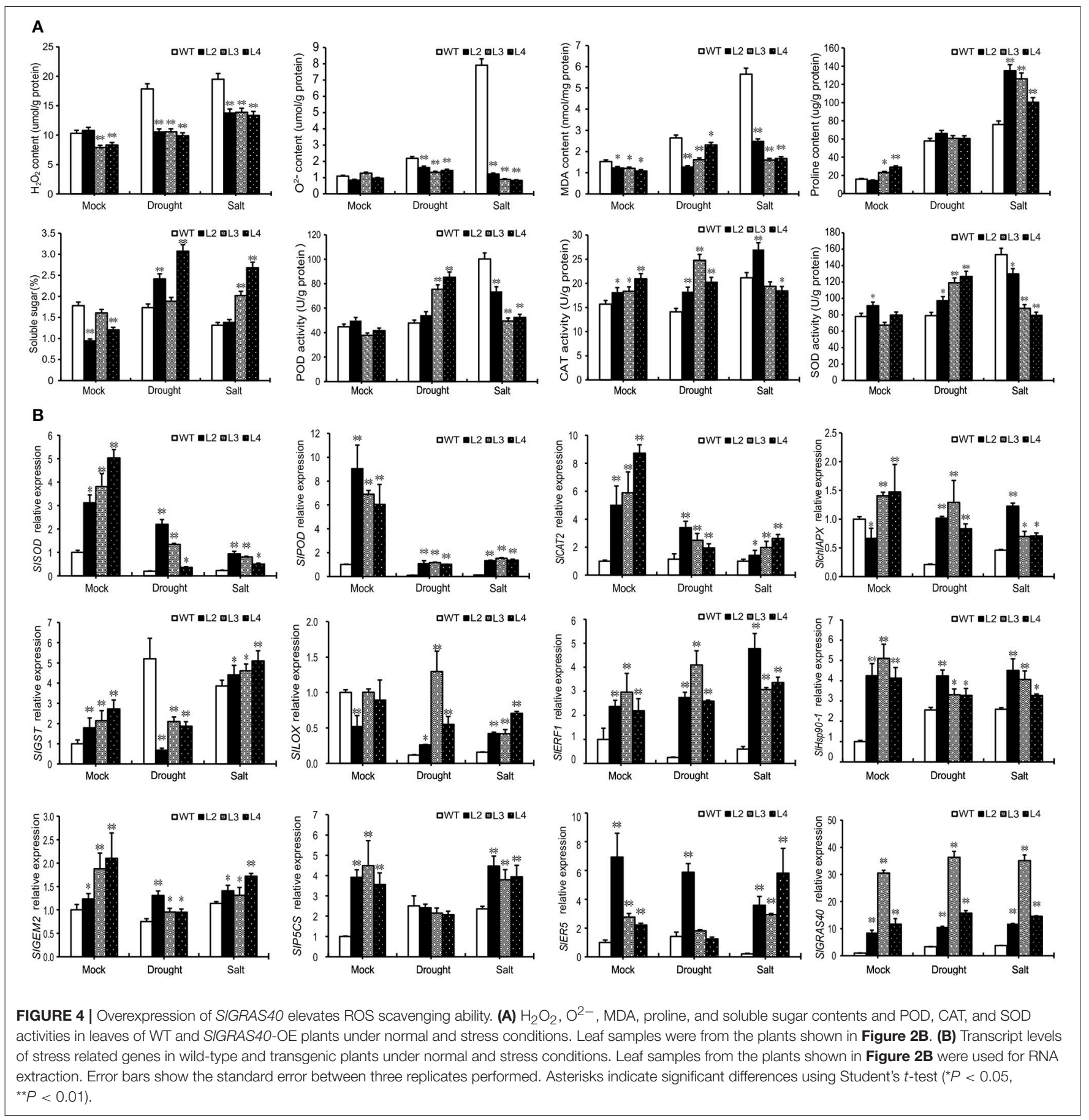

(Figure 8B). In pollen germination and pollen tube growth assays, the pollen from transgenic plants (OE L3) germinated normally and the pollen tube grew like WT. In OE L3 plants pollen tubes could grow through the stigma and style into the ovary, and then spread out toward the ovules as occurs in WT plants (Figure 8C). When emasculated ovaries (L3) were treated with 2,4-D or $\mathrm{GA}_{3}$ on the day equivalent to anthesis (0 dpa), fruit-set ratio and fruit size increased significantly (Figure 8D, Supplementary Figure S2), indicating that disruption of fertilization caused by SIGRAS40 overexpression is related to altered auxin and gibberellin responses in SlGRAS40-OE pollinated ovaries.

\section{Differential Expression of Genes Related to Auxin and GA in SIGRAS40-OE Plants}

The expression of a range of genes related to auxin and GA was assessed in WT and OE L3 seedlings treated with IAA and $\mathrm{GA}_{3}$ for $3 \mathrm{~h}$ (Supplementary Figure S3). Expression of the 


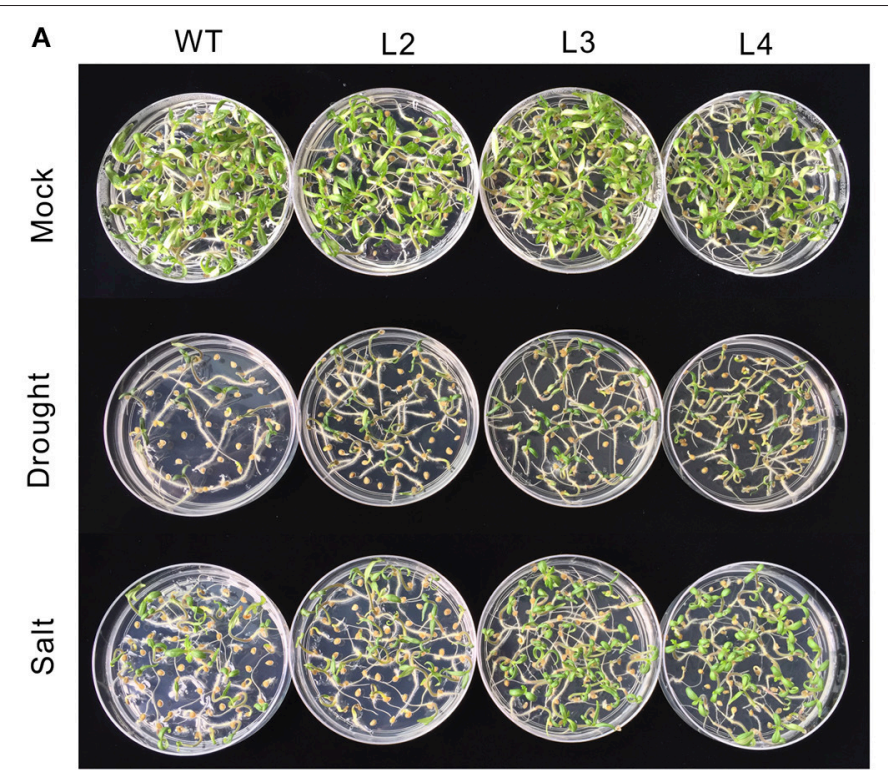

C

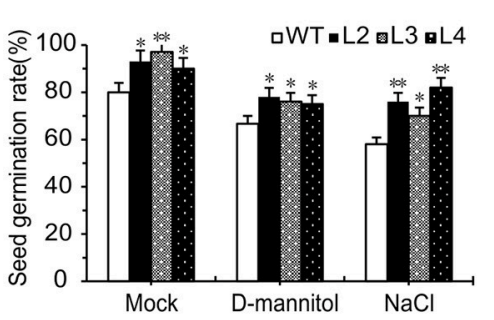

D

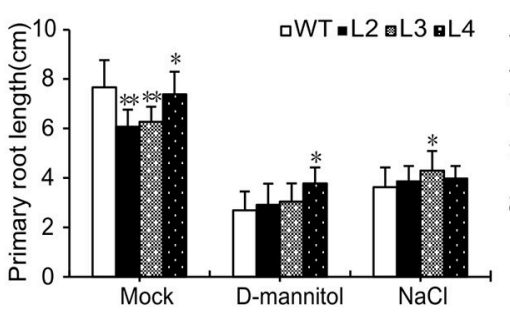

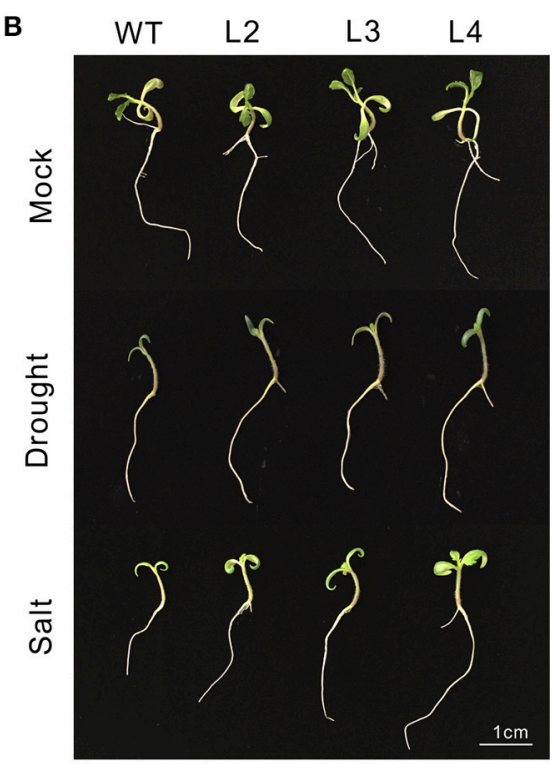

E

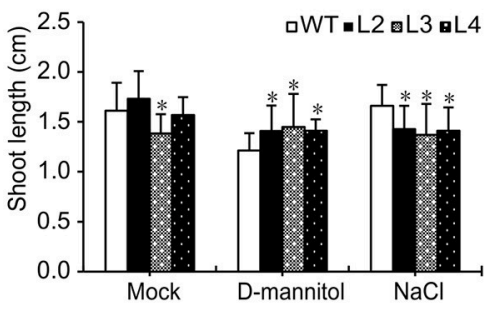

FIGURE 5 | Comparative analysis of WT and SIGRAS4O-OE lines under drought and salt stress. (A, B) Seed germination of WT and SIGRAS40-OE lines after 2 weeks in medium containing $150 \mathrm{mM} \mathrm{D-mannitol} \mathrm{or} 75 \mathrm{mM} \mathrm{NaCl}$. (C) Germination rate of WT and S/GRAS4O-OE lines under control and drought or salt treatments. (D) Primary root length of WT and SIGRAS4O-OE seedlings under control and drought or salt treatments. (E) Shoot length of WT and SIGRAS4O-OE seedlings under control and drought or salt treatments. Error bars show the standard errors between three replicates. Asterisks indicate significant differences using Student's t-test $\left({ }^{\star} P<0.05,{ }^{\star \star} P<0.01\right)$.

following genes were tested: SlIAAs, SlARFs, SlPINs, SlTIR1s, SlAFBs, and $S l G H 3$, all involved in auxin signaling; SlGA20ox1, 3 and 4, SlGA3ox1 and 2, and SlGA2ox1, 2, 3, 4, and 5; genes encoding gibberellin receptors SlGAST and SlGID1; genes encoding gibberellin synthetases SlKS, SlKAO, SlKO, SlCPS, SlGPS; and SIDELLA, which is an inhibitor of gibberellin signaling. All these genes differed in how they were expressed in WT and OE seedlings. SlPINs, SlTIR1s, SlAFBs, SlKO, and SlGPS were all down-regulated in OE seedlings compared to WT. Also some genes responded differently after treatment with IAA or $\mathrm{GA}_{3}$ between OE and WT seedlings. SIIAA4, SIIAA7, SIIAA9, SlARF5, and SlKS were all up-regulated after $\mathrm{GA}_{3}$ treatment in WT, but were down-regulated in OE seedlings (Supplementary Figure S3). SIARF6 was down-regulated in WT after IAA treatment, and up-regulated in OE seedlings. SlAFB4 was downregulated in WT after $\mathrm{GA}_{3}$ and IAA treatment, but up-regulated in OE seedlings. SIDELLA was up-regulated after $\mathrm{GA}_{3}$ and IAA treatment in WT, but down-regulated in OE seedlings after IAA treatment (Supplementary Figure S3). SlGID1 and SlGAST were up-regulated after IAA treatment in WT, but down-regulated in OE seedlings compared with untreated seedlings. SlGA2ox3 was strongly up-regulated in WT, but significantly downregulated in $\mathrm{OE}$ after $\mathrm{GA}_{3}$ treatment. These results showed that overexpression of SlGRAS40 altered the expression levels of genes involved in auxin and GA signaling, suggesting that SlGRAS40 is involved in regulating the biosynthesis and/or signaling of auxin and GA in tomato.

\section{Expression Levels of Genes Related to Fruit Set Were Altered in SIGRAS40-OE Plants}

In normal fruit development, the initiation of fruit set depends on the successful completion of pollination and fertilization, corresponding with a rise in levels of auxin and GA in pollinated ovaries (Serrani et al., 2007b). We compared gene expression of auxin and GA signaling genes related to fruit set in -2 , 0 , and 4 dpa ovaries, and ovaries treated with 2,4-D, or $\mathrm{GA}_{3}$ for 4 days (Supplementary Figure S4). All the auxin related genes have lower expression in $0 \mathrm{dpa} \mathrm{OE}$ ovaries compared 


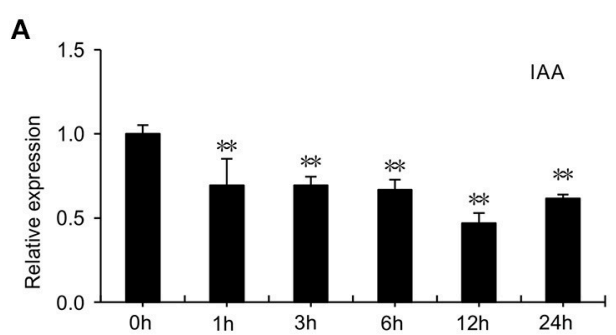

B

IAA

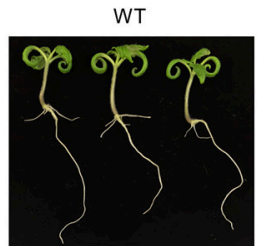

AA

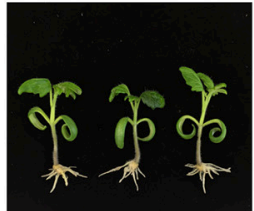

$\mathrm{A}_{3}$
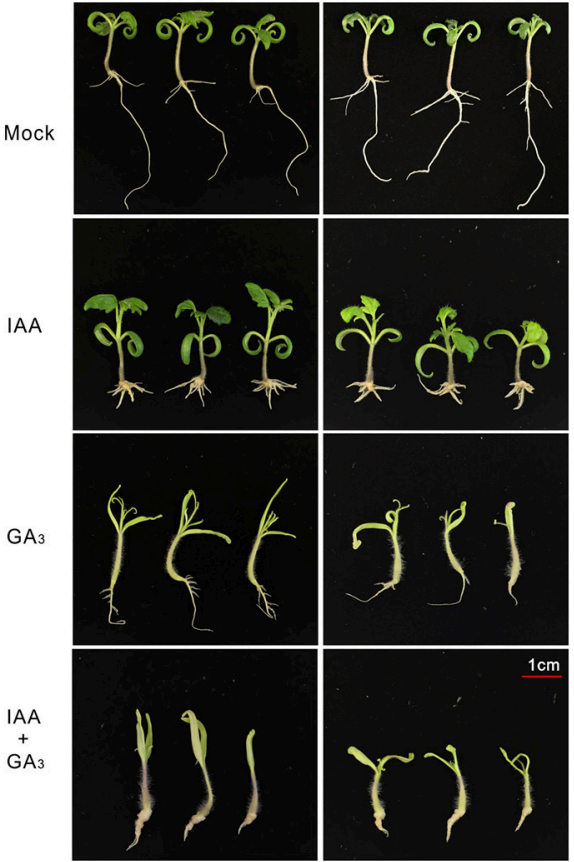

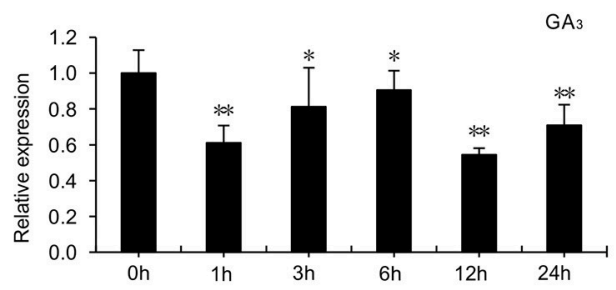

C
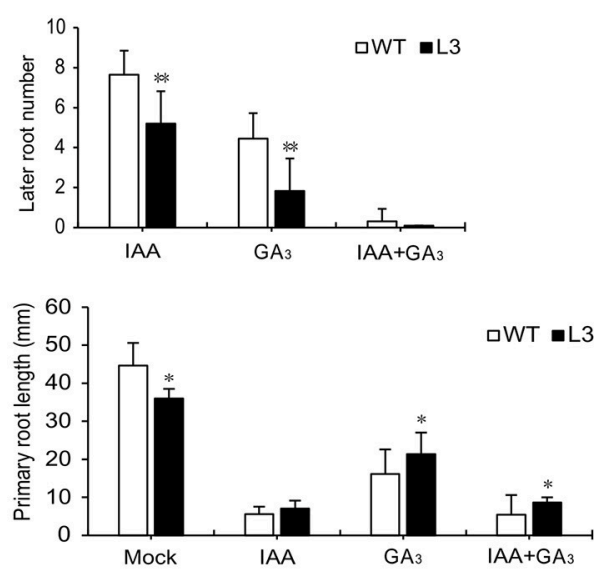

E

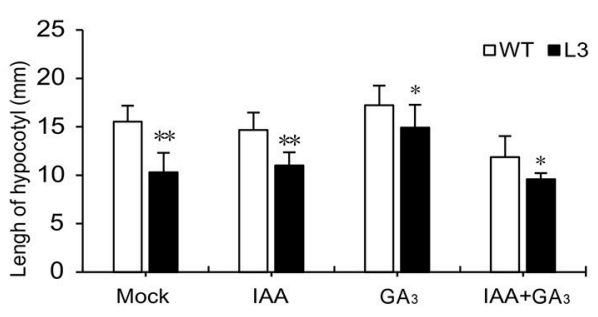

$\mathbf{F}$

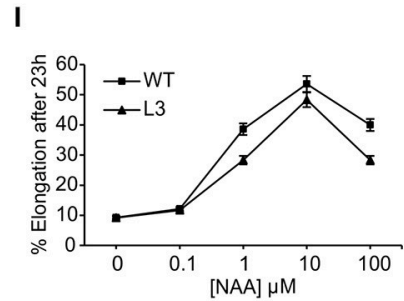

G

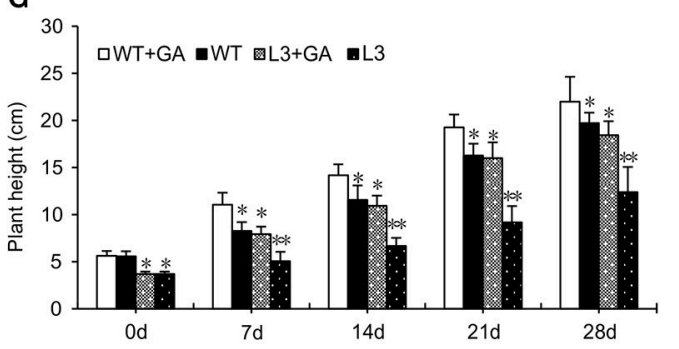

H

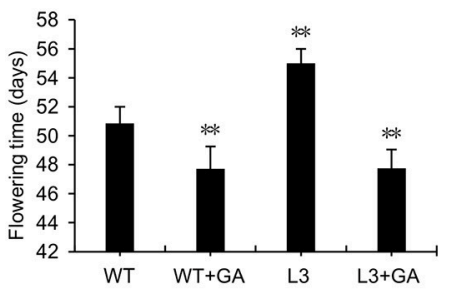

FIGURE 6 | Overexpression of SIGRAS40 alters responsiveness to IAA and GA 3 . (A) Quantitative RT-PCR analysis of SIGRAS40 mRNA from leaves of 15-day-old WT seedlings treated with $20 \mu \mathrm{M}$ IAA and $20 \mu \mathrm{M}$ GA 3 . (B) Phenotypes of 15-day-old WT and S/GRAS40-OE L3 seedlings grown on $1 / 2 \times$ MS medium containing $1 \mu \mathrm{M}$ $I A A$ and/or $50 \mu \mathrm{M} \mathrm{GA}_{3}$. (C) Number of lateral roots of WT and SIGRAS40-OE L3 seedlings treated with IAA, GA 3 or IAA + GA 3 . (D) Primary root length of WT and SIGRAS40-OE L3 seedlings shown in (B). (E) Hypocotyl length of WT and SIGRAS40-OE L3 seedlings shown in (B). (F) Rescue of SIGRAS40-OE L3 dwarfism by exogenous $\mathrm{GA}_{3}$ application. (G) Plant height and (H) Phase transition time of $\mathrm{GA}_{3}$ treated plants shown in (F). (I) Hypocotyl elongation of WT and S/GRAS40-OE L3 after NAA treatment. Asterisks indicate significant differences using Student's $t$-test $\left({ }^{\star} P<0.05,{ }^{\star \star} P<0.01\right)$. 


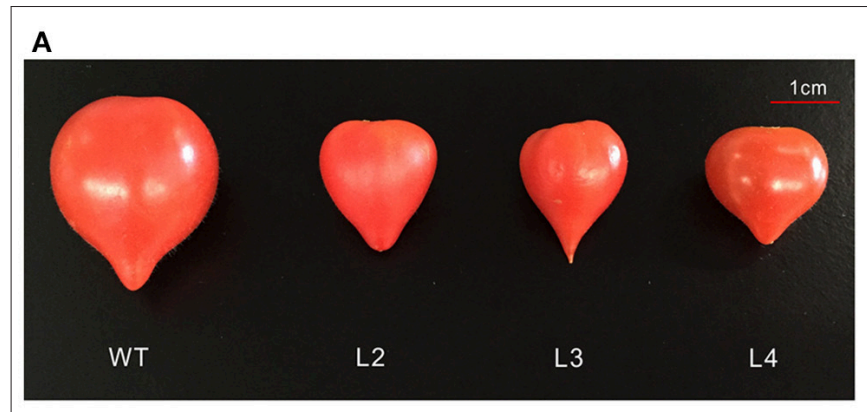

B

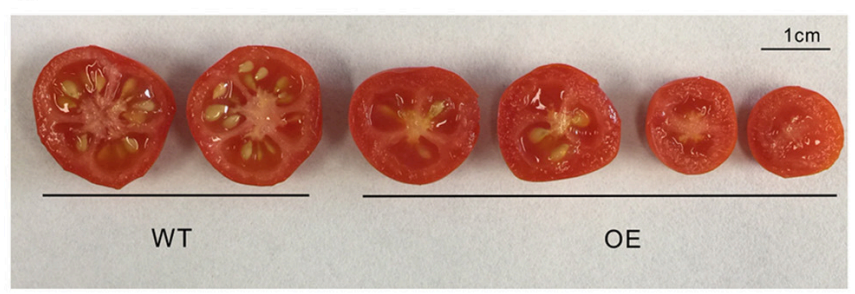

c

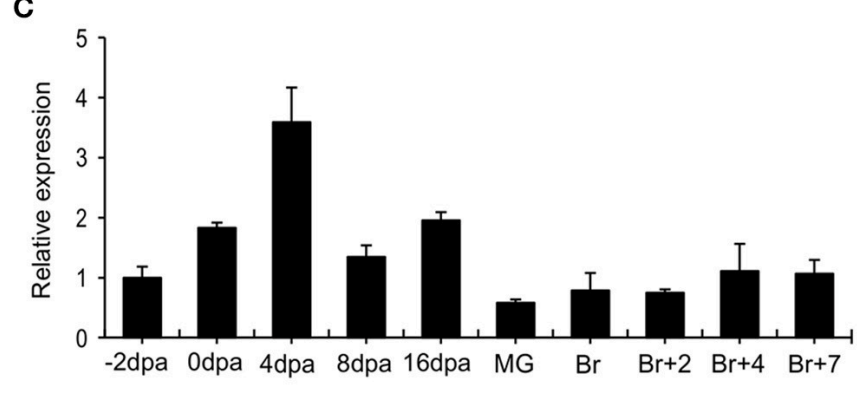

I

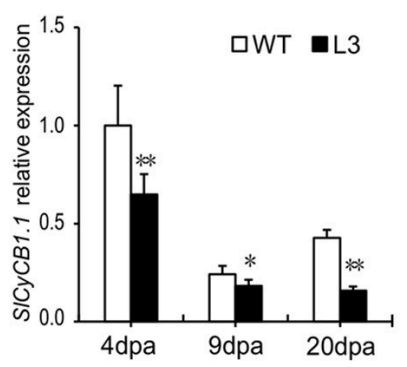

D

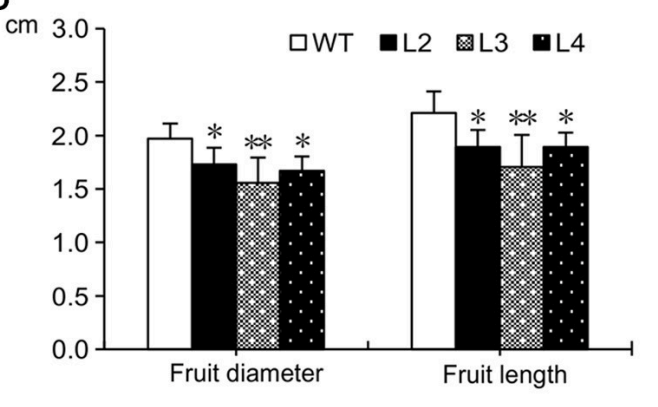

E

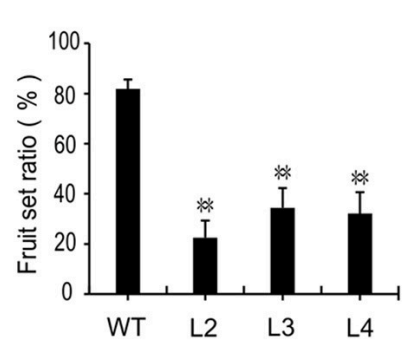

F

G
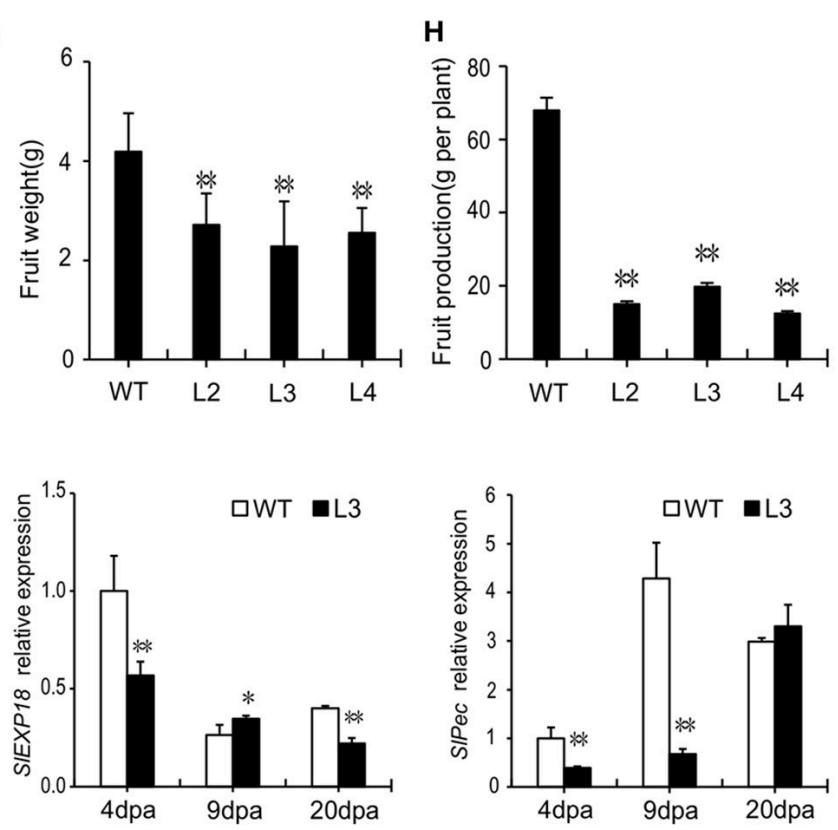

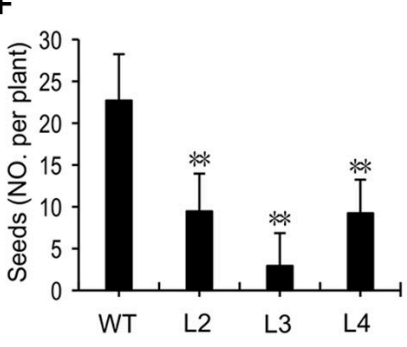

H

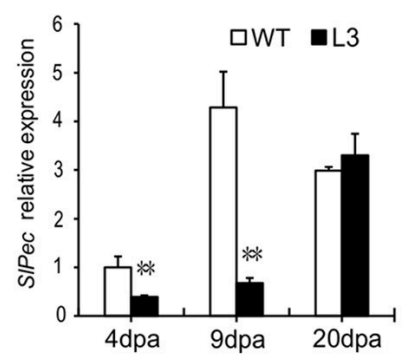

FIGURE 7 | SIGRAS40-OE plants bear smaller fruits with fewer seeds. (A,B) Fruits of WT and SIGRAS40-OE plants. (C) Tissue profiling of SIGRAS40 in different stage ovaries and fruits of wild-type tomato. dpa, days post anthesis; MG, mature green fruit; Br, color breaker fruit. The expression data was normalized with the value for -2 dpa ovary set to 1. (D) Diameter and length of WT and S/GRAS4O-OE fruits in (A). (E) Fruit set ratio, (F) Seed number, (G) Fruit weight, and (H) Fruit production of WT and SIGRAS40-OE fruits. Error bars show the standard error of values from three biological replicates $(n=3)$ with more than 20 fruits or 20 plants per replicate. (I) Quantitative RT-PCR analysis of cell division and expansion genes in 4, 9, and 20 dpa WT and SIGRAS40-OE L3 fruits. dpa, days post anthesis. Error bars show the standard error between three replicates. Asterisks indicate significant differences using Student's $t$-test ${ }^{\star} P<0.05$, $\left.{ }^{\star \star} P<0.01\right)$.

with WT. SIIAA9 was up-regulated in WT but down-regulated in OE ovaries after $\mathrm{GA}_{3}$ treatment. SlGA20ox4, SlGA3ox1, 2 , and SlGPS had higher expression levels at -2 dpa that decreased rapidly at $0 \mathrm{dpa}$ in $\mathrm{OE}$ ovaries compared with WT (Supplementary Figure S4). SlGA2ox1, 3, and 4 were all upregulated in -2 dpa OE ovaries, especially SlGA2ox1, which had a higher level in 0 dpa OE ovaries compared with WT
(Supplementary Figure S4). SlGID1 was expressed at a higher level in -2 dpa OE ovaries, but at a lower level at 0 dpa than in comparable WT fruit (Supplementary Figure S4). SIDELLA was upregulated in -2 and 0 dpa OE ovaries compared to WT. The disturbed fertilization in SIGRAS40-OE plants may have been due to the disruption in these auxin and gibberellin related genes. 

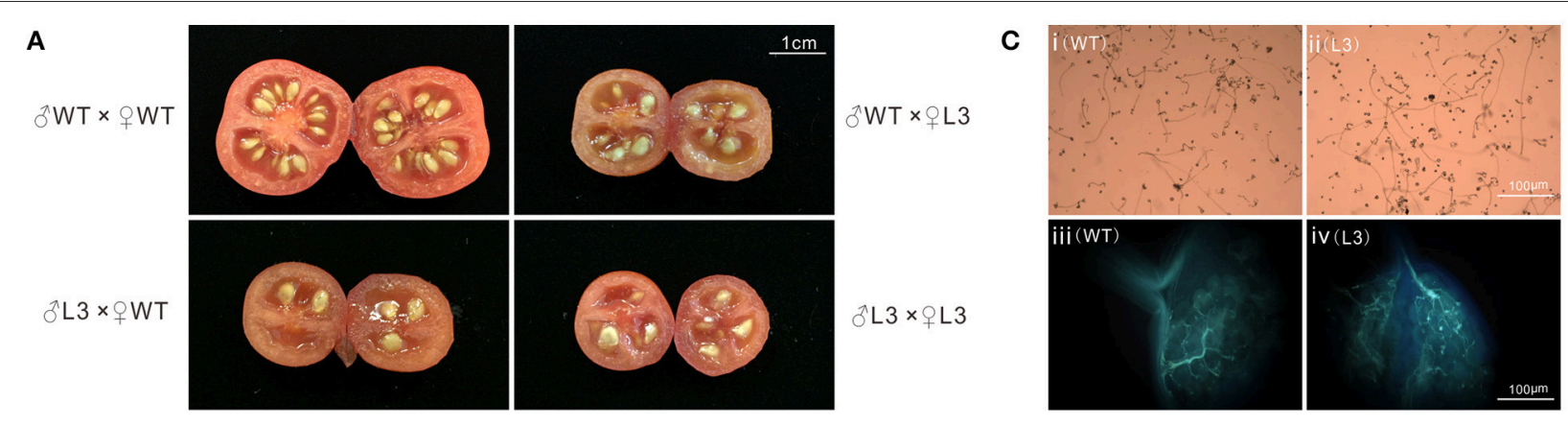

B

\begin{tabular}{|c|c|c|c|c|c|}
\hline Cross & $\begin{array}{l}\text { Fruit set (Fruits } \\
\text { Developed/ } \\
\text { No. of } \\
\text { Attempts) }\end{array}$ & $\begin{array}{l}\text { Fruit } \\
\text { set } \\
\text { ratio } \\
(\%) \\
\end{array}$ & $\begin{array}{l}\text { Seeds } \\
\text { (No. } \\
\text { per fruit) }\end{array}$ & $\begin{array}{l}\text { Fruit } \\
\text { diameter } \\
(\mathrm{cm})\end{array}$ & $\begin{array}{l}\text { Fruit } \\
\text { weight } \\
\text { (g) }\end{array}$ \\
\hline$\sigma^{\prime W T} \times Q W T$ & $19 / 20$ & 95 & $38.6 \pm 3.1$ & $2.2 \pm 0.2$ & $5.2 \pm 0.8$ \\
\hline$\sigma^{\prime \prime} \mathrm{L} 3 \times 9 \mathrm{~L} 3$ & $6 / 20$ & 30 & $6.7 \pm 0.8$ & $1.6 \pm 0.2$ & $2.5 \pm 0.3$ \\
\hline$\sigma^{\prime} \mathrm{L} 4 \times$ × $\mathrm{L} 4$ & $7 / 20$ & 35 & $7.0 \pm 0.1$ & $1.6 \pm 0.1$ & $2.3 \pm 0.6$ \\
\hline o"L3 × $q \mathrm{WT}$ & $10 / 13$ & 77 & $5.6 \pm 0.4$ & $1.6 \pm 0.2$ & $2.0 \pm 0.5$ \\
\hline$\sigma^{\prime \prime} L 4 \times$ × WT & $13 / 18$ & 72 & $9.0 \pm 1.2$ & $1.7 \pm 0.2$ & $2.4 \pm 0.5$ \\
\hline o'WT $\times$ Q $L 3$ & $12 / 20$ & 60 & $17.0 \pm 1.9$ & $1.7 \pm 0.2$ & $2.7 \pm 0.8$ \\
\hline 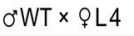 & $11 / 18$ & 61 & $14.0 \pm 1.6$ & $1.6 \pm 0.3$ & $2.6 \pm 0.3$ \\
\hline
\end{tabular}

D
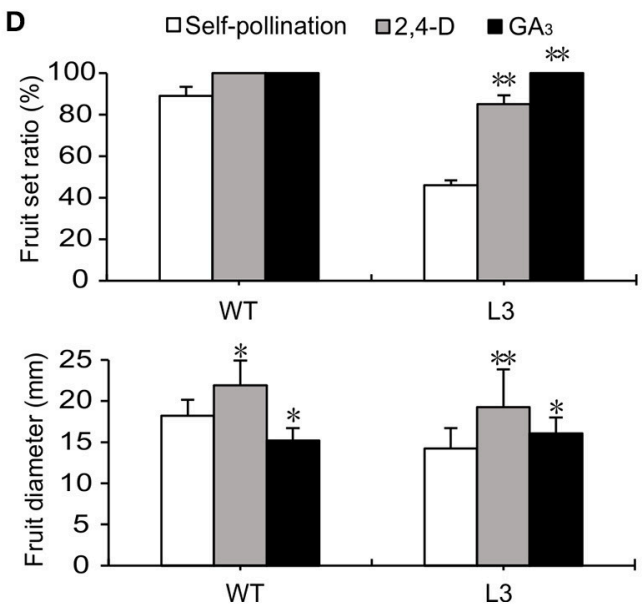

FIGURE 8 | Overexpression of SIGRAS40 disturbs fertilization. (A) Images of cross-fertilization assay. (B) Cross-fertilization assay data. (C) Pollen germination (i, ii) and pollen tube growth (iii, iv) of WT (i, iii) and SIGRAS4O-OE L3 (ii, iv) plants. (D) Fruit-set ratio and fruit diameter of WT and SIGRAS4O-OE L3 plants treated with 2,4-D and $\mathrm{GA}_{3}$ for 20 days. Error bars show the standard error between three biological replicates $(n=3)$ with more than eight ovaries per replicate. Asterisks indicate significant differences using Student's $t$-test $\left({ }^{\star} P<0.05,{ }^{\star \star} P<0.01\right)$.

\section{Overexpression of SIGRAS40 Modifies Expression of Genes Involved in Hormone Signaling and Stress Responses in SAM}

To identify the changes in transcript levels of genes regulated by SlGRAS40, a comparative transcriptome analysis was conducted using shoot apical meristems (SAM) of 1-month-old SlGRAS40OE L3 plants and WT controls. A total of 338 DEGs were identified, 169 upregulated and 169 downregulated (Figure 9A, Supplementary Table S3). A total of 30 GO terms (Supplementary Table S4) and 18 KEGG pathways (Supplementary Table S5) were enriched in the transcriptome of tomato overexpressing SlGRAS40. The top 10 GO terms (Figures 9B,C) and KEGG pathways (Figures 9D,E) were detailed in Figure 9. Overexpression of SlGRAS40 influenced multiple processes including stress responses, phytohormone biosynthesis, signal transduction, transcription, primary and secondary metabolite biosynthesis, photosynthesis, and so on. There were 17 DEGs involved in hormone signaling including auxin, gibberellin, ethylene and abscisic acid, indicated hormones crosstalk may be influenced by SlGRAS40. And many transcription factors (TFs) were found in the data, including stress response transcription factors, such as NAC,
WRKY, ERF, and MYB. Besides, such DEGs encoding positive regulators of stress resistance were induced by SlGRAS40 overexpression, such as endochitinase, beta-amylase, polyphenol oxidase, zeaxanthin epoxidase and osmotin protein (Table 1), indicated the possible molecular mechanism that overexpression of SlGRAS40 influences plant development and enhances abiotic resistance. A total of 9 genes were selected for supplementary qRT-PCR analysis (Supplementary Figure S5). For all the genes tested, qRT-PCR analysis validated the transcriptomic data. Sequencing clean data were uploaded to sequence read archive (SRA), the accession number was SRP115441.

\section{A Hypothesized Model of SIGRAS40 Enhances Abiotic Resistance Interlinked with Auxin and Gibberellin}

SlGRAS40 overexpressing plants displayed GA deficiency and auxin insensitivity (Figure 6). As GA biosynthesis-activating enzymes, SlGA20ox1, SlGA20ox3, SlGA20ox4 and SlGA3ox1, SlGA3ox2 were significant suppressed in SlGRAS40-OE plants (Supplementary Figure S2), may be induced lower bioactive GAs level in OE plants. And the expression of auxin receptors (SlTIR1A, SITIR1B, SlAFB4, and SIAFB6) and auxin transporters 


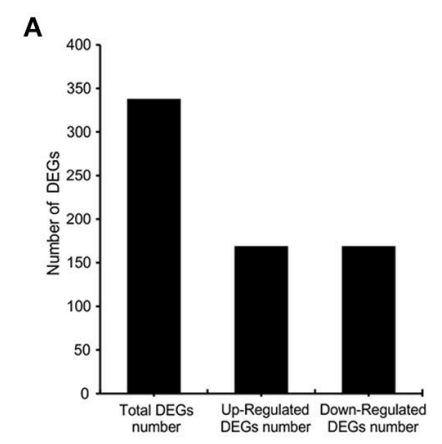

B

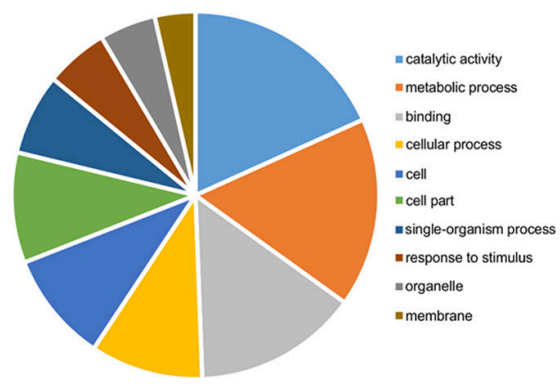

C

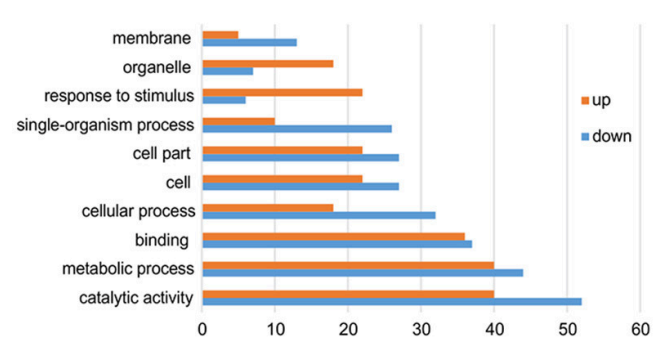

D

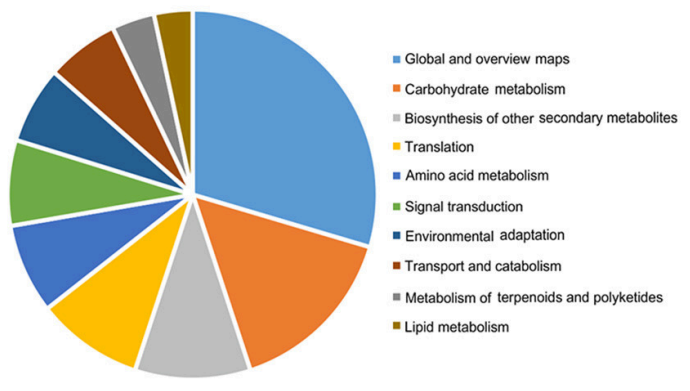

E

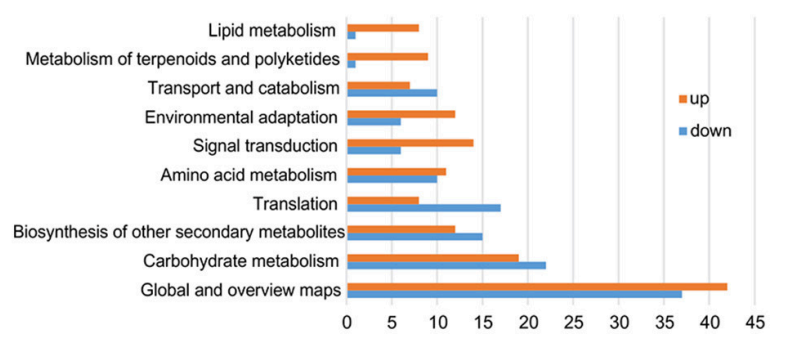

FIGURE 9 | Classification of DEGs in RNA-Seq data. (A) The number of DEGs from the RNA-Seq data. (B,C) The top 10 GO terms of DEGs between SIGRAS40-OE L3 and WT. (D,E) The top 10 KEGG pathways of DEGs between SIGRAS4O-OE L3 and WT.

(SlPIN3 and SlPIN6) were also significant suppressed in SlGRAS40-OE plants (Supplementary Figure S2), suggested which impact auxin signaling in $\mathrm{OE}$ plants. These results indicated that overexpression of SlGRAS40 in tomato disrupted auxin and gibberellin homeostasis and signaling. Accordingly, under abiotic stresses, we predicted that SIGRAS40 influence auxin and gibberellin crosstalk, and enhance ROS scavenging ability mediated by DELLA stability in plant cells, and then empowered abiotic resistance in SIGRAS40-OE plants, and a proposed model was depicted in Figure 10.

\section{DISCUSSION}

\section{SIGRAS40-OE Improved Resistance to Drought and Salt via Enhanced Ability to Scavenge ROS}

Drought and salt stress can decrease photosynthetic capacity, augment oxidative damage to cells, and limit metabolic reactions
(Farooq et al., 2009). In this work, damage symptoms in tomato plants, including wilting, chlorosis, and necrosis, were delayed in SlGRAS40-OE compared to WT under saline or drought stress (Figure 2B). Levels of RWC and total chlorophyll content were significantly higher in OE plants than in WT (Figures 2D-G). Seed germination rate and seedling root growth were less affected by $\mathrm{D}$-mannitol and $\mathrm{NaCl}$ treatments in $\mathrm{OE}$ than in WT (Figure 5). These results suggested that overexpression of SlGRAS40 enhanced the resistance to drought and salt stress during vegetative growth.

Abiotic and biotic stresses can trigger oxidative stress in plant cells (Dat et al., 2000) and the ROS generated may cause cell death if not adequately removed. The steady-state level of ROS within the cell represents a balance between the total reactive oxygen produced and the capacity of cellular antioxidant systems to remove it through both enzymatic and non-enzymatic means (Foyer and Noctor, 2005). In our research, $\mathrm{H}_{2} \mathrm{O}_{2}$ and $\mathrm{O}_{2}^{-}$ contents were significantly lower in SlGRAS40-OE plants than in WT after drought and salt treatment (Figure 4A). 


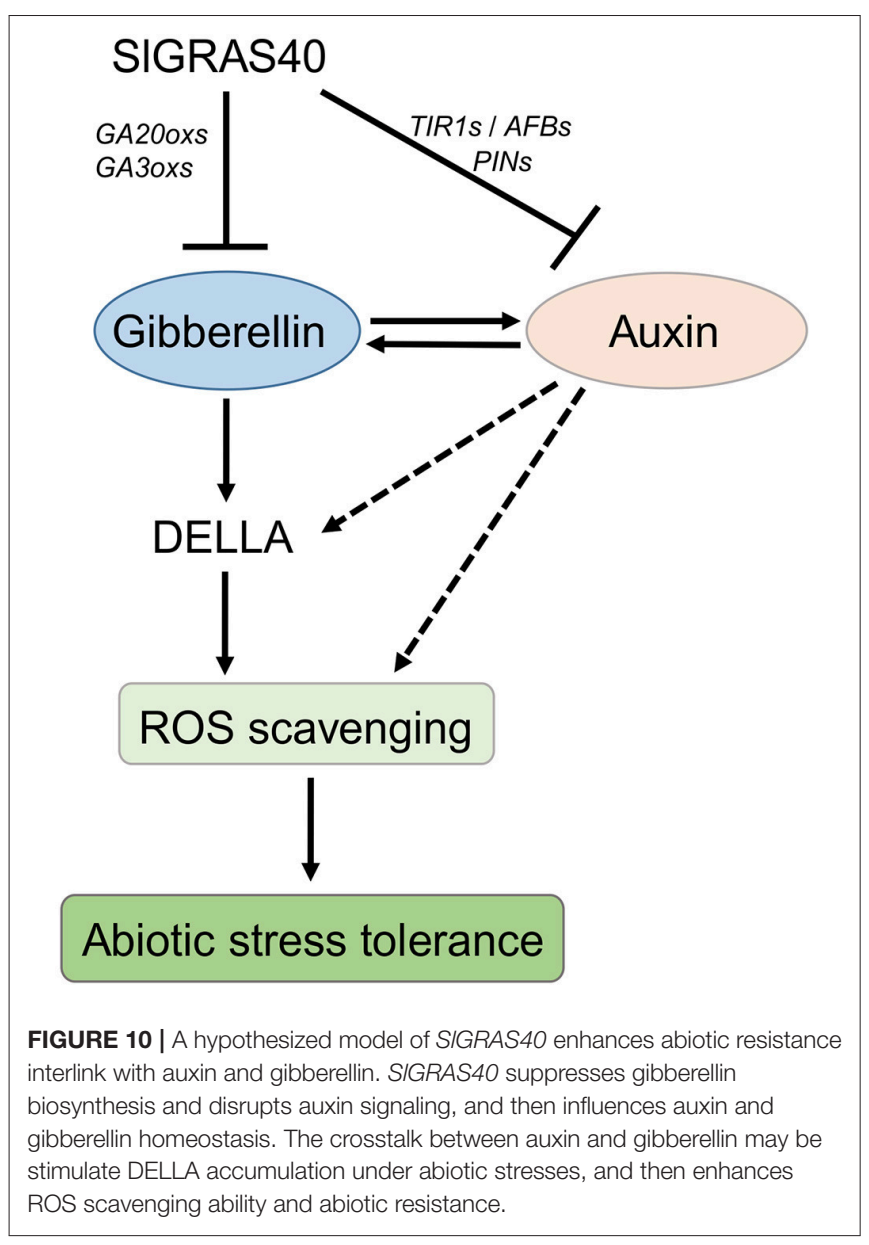

We hypothesized that SIGRAS40-OE plants had a better ROS scavenging ability. Ascorbate, glutathione, alkaloids, proline, and carbohydrates (Chen et al., 2007) act non-enzymatically as cellular redox buffers in plant cells (Apel and Hirt, 2004). SlGRAS40-OE plants accumulated more proline and soluble sugar than WT plants in response to both stresses. The MDA content increased significantly, a sign of oxidative damage, in WT plants under drought and salt stress conditions, but only a slight increase was observed in OE plants (Figure 4A). It is likely then that proline and soluble sugar protect SIGRAS40-OE against ROS, minimizing oxidative damage.

ROS scavenging enzymes in plants, including SOD, APX, CAT, POD, and GST, alleviate oxidative damage and enhance plant stress tolerance (Apel and Hirt, 2004). In this study, under normal and drought conditions, CAT activity was higher in $\mathrm{OE}$ plants than in WT (Figure 4A), and the activities of POD and SOD in SlGRAS40-OE plants were up-regulated under drought stress, but were unchanged in WT plants (Figure 4A). After salt treatment, activities of CAT, POD, and SOD were significantly up-regulated in WT plants, whereas OE plants had lower levels of these three activities (Figure 4A). There may be other antioxidant systems that play roles under salt stress in SlGRAS40-OE plants, but these data indicate that the ROS scavenging ability in SlGRAS40-OE plants was broadly enhanced.

Numerous genes have been reported to be upregulated under stress conditions in vegetative tissues (Seki et al., 2002;
Zhu, 2002). In our research, the transcript levels of several genes involved in ROS scavenging were monitored (Figure 4B). Transcript levels of SlchlAPX, SlCAT2, SISOD, SlPOD, and SlLOX plants were higher in SlGRAS40-OE than in WT both in control and stress treatments (Figure 4B). SlGME2, which encodes an important catalytic enzyme in ascorbic acid biosynthesis (Zhang C. J. et al., 2011), and SlP5CS, a key proline synthetase gene (Vendruscolo et al., 2007), accumulated more in OE plants than in WT both in normal and stress conditions (Figure 4B). SlERF1, an important regulator of abiotic/biotic stress responses (Lu et al., 2010), and the heat shock protein SlHsp90-1 both had higher expression levels in OE plants after drought and salt stress treatment than in WT (Figure 4B). These results indicate that SlGRAS40 modulates the expression of genes involved in stress signaling pathways, which might be a mechanism of enhancing the tolerance of drought and salt stress.

\section{Does SIGRAS40 Integrate Phytohormone-Regulated Growth and Stress Responses in Tomato?}

Auxin and gibberellin have roles in abiotic stress responses in plants. For example, salt-activated ethylene and ABA signaling pathways integrate at the level of DELLAs to promote salt tolerance (Achard et al., 2006). DELLA proteins are also involved in ROS reactions and coordination of development during abiotic stress (Achard et al., 2008). Salt or mannitol treatment can enhance accumulation of DELLAs accompanied by upregulation of the genes encoding antioxidant systems, followed by a drop in ROS abundance (Apel and Hirt, 2004; Achard et al., 2006). A correlation has been made between endogenous auxin levels and abiotic stress responses in rice where overexpression of OsPIN3t or OsGH3.13 increased tolerance to drought (Zhang et al., 2009, 2012). Previous studies also suggested that there is signaling reciprocity between auxin and ROS pathways. Exogenous application of auxin reduced the $\mathrm{H}_{2} \mathrm{O}_{2}$ content in tomato roots by increasing the expression and activity of $\mathrm{H}_{2} \mathrm{O}_{2}$ scavenging enzymes (Tyburski et al., 2009).

Some GRAS function as regulators of auxin and gibberellin in plant growth and development. In our previous study, we characterized how SIGRAS24 impacted multiple agronomical traits by regulating auxin and gibberellin homeostasis in tomato (Huang et al., 2017). In the present work, overexpression of SIGRAS40 altered the responsiveness to IAA and $\mathrm{GA}_{3}$ (Figure 6B); led to auxin insensitivity and GA deficiency, and altered the abundance of transcripts related to auxin/gibberellin biosynthesis and signaling (Supplementary Figure S3). This is compelling evidence that SlGRAS40 acts as a regulator of auxin and GA. We speculate that SlGRAS40 regulates the response to abiotic stress in plant through auxin and/or GA signaling. A hypothesized model was shown in Figure 10, SlGRAS40 suppresses gibberellin biosynthesis by decreasing the expression of genes encoding GA biosynthesis-activating enzymes, and disrupts auxin signaling by decreasing the expression of genes encoding auxin receptors and transporters, and then influences auxin and gibberellin homeostasis. Accordingly, we predict that the crosstalk between auxin and gibberellin may be stimulate DELLA accumulation under abiotic stresses in SlGRAS40-OE 
TABLE 1 | List of DEGs related to hormone signaling, transcription factor and stress response between WT and SIGRAS4O-OE L3 tomato SAM (L3/WT, fold change $\geq 2.00$ and probability $\geq 0.8$ ).

\begin{tabular}{|c|c|c|c|}
\hline Gene ID & Functional annotation & $\log 2$ Fold & Probability \\
\hline \multicolumn{4}{|c|}{ HORMONE SIGNALING } \\
\hline Solyc07g041720.1.1 & $\begin{array}{l}\text { Auxin-binding protein } \\
\text { ABP19a-like }\end{array}$ & 1.51 & 0.87 \\
\hline Solyc03g123410.1.1 & Auxin-binding protein $\mathrm{ABP} 19 \mathrm{a}$ & 1.30 & 0.80 \\
\hline Solyc10g011660.2.1 & $\begin{array}{l}\text { Indole-3-acetic acid-amido } \\
\text { synthetase GH3.5 }\end{array}$ & 1.43 & 0.84 \\
\hline Solyc10g008520.2.1 & Auxin-responsive GH3-like & 1.31 & 0.82 \\
\hline Solyc12g007230.1.1 & IAA8 protein & -1.24 & 0.83 \\
\hline Solyc06g008590.2.1 & IAA10 protein & -1.61 & 0.86 \\
\hline Solyc04g052910.1.1 & SAUR family protein & -9.84 & 0.83 \\
\hline Solyc10g076680.1.1 & Gibberellin 3-beta-dioxygenase & 9.69 & 0.81 \\
\hline Solyc06g008870.2.1 & Gibberellin receptor GID1B-like & 1.44 & 0.81 \\
\hline Solyc06g069790.2.1 & $\begin{array}{l}\text { Gibberellin-regulated protein } \\
6 \text {-like }\end{array}$ & 1.27 & 0.83 \\
\hline Solyc02g083880.2.1 & $\begin{array}{l}\text { Gibberellin-regulated } \\
\text { protein } 11\end{array}$ & 1.32 & 0.84 \\
\hline Solyc03g116060.2.1 & Gibberellin-regulated protein 6 & -1.21 & 0.80 \\
\hline Solyc01g095140.2.1 & $\begin{array}{l}\text { Ethylene-responsive late } \\
\text { embryogenesis-like protein }\end{array}$ & 2.02 & 0.89 \\
\hline Solyc09g075420.2.1 & Ethylene-binding protein & 1.29 & 0.83 \\
\hline Solyc11g012980.1.1 & $\begin{array}{l}\text { Ethylene-responsive } \\
\text { transcription factor ERF014 }\end{array}$ & -3.48 & 0.82 \\
\hline Solyc01g095700.2.1 & Abscisic acid receptor PYL8 & 1.45 & 0.85 \\
\hline Solyc03g095780.1.1 & $\begin{array}{l}\text { Abscisic acid receptor } \\
\text { PYL4-like }\end{array}$ & 1.30 & 0.81 \\
\hline \multicolumn{4}{|c|}{ TRANSCRIPTION FACTORS } \\
\hline Solyc05g009310.2.1 & $\begin{array}{l}\text { Zinc finger protein } \\
\text { CONSTANS-LIKE 16-like }\end{array}$ & 1.99 & 0.83 \\
\hline Solyc01g111500.2.1 & MYB-related protein 308-like & 1.78 & 0.81 \\
\hline Solyc11g006720.1.1 & $\begin{array}{l}\text { Transcription factor } \\
\text { DIVARICATA }\end{array}$ & 1.76 & 0.83 \\
\hline Solyc03g034000.2.1 & Transcription factor BEE 2 & 1.68 & 0.81 \\
\hline Solyc08g076820.2.1 & Hop-interacting protein THI018 & 1.58 & 0.83 \\
\hline Solyc03g111710.2.1 & $\begin{array}{l}\mathrm{BTB} / \mathrm{POZ} \text { and TAZ } \\
\text { domain-containing protein } 1\end{array}$ & 1.48 & 0.84 \\
\hline Solyc01g086870.2.1 & $\begin{array}{l}\text { Transcription factor } \\
\text { bHLH130-like }\end{array}$ & 1.34 & 0.82 \\
\hline Solyc01g107190.2.1 & $\begin{array}{l}\text { LOB domain-containing } \\
\text { protein } 37 \text {-like }\end{array}$ & 1.28 & 0.81 \\
\hline Solyc02g092930.1.1 & $\begin{array}{l}\text { Transcription factor } \\
\text { MYB44-like }\end{array}$ & -1.25 & 0.82 \\
\hline Solyc04g015360.2.1 & GATA transcription factor 8 & -1.37 & 0.81 \\
\hline Solyc10g005080.2.1 & $\begin{array}{l}\text { MYB-related transcription } \\
\text { factor LHY }\end{array}$ & -1.47 & 0.82 \\
\hline Solyc05g056620.1.1 & $\begin{array}{l}\text { MADS-box transcription factor } \\
\text { MADS-MC }\end{array}$ & -1.63 & 0.82 \\
\hline Solyc11g012980.1.1 & $\begin{array}{l}\text { Ethylene-responsive } \\
\text { transcription factor ERF014 }\end{array}$ & -3.48 & 0.82 \\
\hline \multicolumn{4}{|c|}{ STRESS RESPONSE (GENES WITH ASTERISKS MEANS TFS) } \\
\hline Solyc09g089520.2.1 & Proteinase inhibitor I-B-like & 8.11 & 0.98 \\
\hline Solyc09g084490.2.1 & $\begin{array}{l}\text { Wound-induced proteinase } \\
\text { inhibitor 1-like }\end{array}$ & 3.79 & 0.90 \\
\hline Solyc09g084480.2.1 & $\begin{array}{l}\text { Wound-induced proteinase } \\
\text { inhibitor 1-like }\end{array}$ & 2.46 & 0.90 \\
\hline Solyc09g083440.2.1 & $\begin{array}{l}\text { Wound-induced proteinase } \\
\text { inhibitor } 1\end{array}$ & 2.20 & 0.88 \\
\hline
\end{tabular}

(Continued)
TABLE 1 | Continued

\begin{tabular}{|c|c|c|c|}
\hline Gene ID & Functional annotation & $\log 2$ Fold & Probability \\
\hline Solyc09g084470.2.1 & Proteinase inhibitor 1 & 1.85 & 0.87 \\
\hline Solyc08g080660.1.1 & Osmotin-like protein OSML15 & 2.68 & 0.86 \\
\hline Solyc10g074440.1.1 & Endochitinase & 2.15 & 0.89 \\
\hline Solyc10g055800.1.1 & Endochitinase 4 & 1.10 & 0.81 \\
\hline Solyc08g077530.2.1 & Beta-amylase 3 & 1.60 & 0.86 \\
\hline Solyc08g074620.1.1 & Polyphenol oxidase E & 1.57 & 0.87 \\
\hline Solyc08g074630.1.1 & Polyphenol oxidase F & 1.03 & 0.81 \\
\hline Solyc04g025650.2.1 z & Zeaxanthin epoxidase & 1.06 & 0.80 \\
\hline $\begin{array}{r}\text { Solyc05g052030.1.1* } \\
t\end{array}$ & $\begin{array}{l}\text { Ethylene response } \\
\text { transcription factor } 4\end{array}$ & 2.46 & 0.88 \\
\hline $\begin{array}{r}\text { Solyc05g052050.1.1 } \\
t\end{array}$ & $\begin{array}{l}\text { Ethylene-responsive } \\
\text { transcription factor } 1\end{array}$ & 2.15 & 0.89 \\
\hline Solyc04g007000.1.1* & Transcription factor RAV1 & 1.90 & 0.87 \\
\hline Solyc04g071770.2.1* & $\begin{array}{l}\text { Ethylene-responsive } \\
\text { transcription factor ABR1-like }\end{array}$ & 1.83 & 0.86 \\
\hline Solyc03g007410.2.1* & $\begin{array}{l}\text { Transcription factor } \\
\text { SPEECHLESS }\end{array}$ & 1.80 & 0.82 \\
\hline Solyc06g060230.2.1* & NAC transcription factor & 1.68 & 0.84 \\
\hline Solyc11g017470.1.1* & NAC transcription factor & 1.44 & 0.83 \\
\hline Solyc02g088340.2.1* & WRKY transcription factor 3 & 3.71 & 0.91 \\
\hline Solyc03g116890.2.1* & WRKY transcription factor 40 & 1.20 & 0.85 \\
\hline Solyc07g008010.2.1* & Transcription factor MYB82 & 1.32 & 0.83 \\
\hline Solyc01g005440.2.1* & $\begin{array}{l}\text { Jasmonate ZIM-domain } \\
\text { protein } 3\end{array}$ & 1.08 & 0.81 \\
\hline Solyc04g077980.1.1* & $\begin{array}{l}\mathrm{C} 2 \mathrm{H} 2 \text {-type zinc finger } \\
\text { transcription factor }\end{array}$ & -1.22 & 0.80 \\
\hline Solyc05g052570.2.1* & $\begin{array}{l}\text { Zinc finger } \mathrm{CCCH} \\
\text { domain-containing protein } \\
\text { 29-like }\end{array}$ & -2.52 & 0.90 \\
\hline Solyc03g026280.2.1* & Transcription factor CBF1 & -4.27 & 0.87 \\
\hline
\end{tabular}

plants, and then enhances ROS scavenging ability and abiotic resistance. And there need more experiments to explore and make sure the network.

The comparative transcriptome analysis of SlGRAS40-OE L3 and WT plants showed that expression of a number of genes involved in auxin and gibberellin signaling were changed by SIGRAS40 overexpression, besides some genes involved in ethylene and abscisic acid signaling also influenced (Table 1), indicated that the balance of phytohormones signaling crosstalk may be disrupted by overexpressing of SlGRAS40 in tomato. On the other hand, the expression of many transcription factors were changed in SlGRAS40-OE plants (Table 1), may be reasons of pleiotropic phenotypes of SlGRAS40-OE plants. Endochitinase (Distefano et al., 2008), beta-amylase (Kaplan et al., 2006), polyphenol oxidase (Mahanil et al., 2008), zeaxanthin epoxidase (Zhang et al., 2016), and osmotin protein were known as positive regulators for stress resistance, these encoding genes were all significant induced by SlGRAS40 overexpression, and many stress response transcription factors (Singh et al., 2002) including MYB, WRKY, NAC, and ERF were also induced expressing in SlGRAS40-OE plants (Table 1). Among these changes could be the way in which SlGRAS40 influences plant development and resistance to abiotic stress.

We also found that overexpression of SlGRAS40 impacted fruit-set ratio and fruit development (Figure 7), including 
expression of genes related to auxin and gibberellin signaling during fruit set (Supplementary Figure S4). Caution should be taken when applying auxin and gibberellin to tomato crops, because these hormones not only modulate stress responses, but also influence plant growth and development, fertilization and fruit development.

Taking together, our study of SlGRAS40 provides evidence that another GRAS potentially plays an integrating role in tomato, regulating resistance to abiotic stresses and auxin and gibberellin signaling during vegetative and reproductive growth.

\section{AUTHOR CONTRIBUTIONS}

ZL, YL, and WH designed the experiments; YL, NH, HR, JC, and DS performed the experiments; YL and DL analyzed the

\section{REFERENCES}

Achard, P., Cheng, H., De Grauwe, L., Decat, J., Schoutteten, H., Moritz, T., et al. (2006). Integration of plant responses to environmentally activated phytohormonal signals. Science 311, 91-94. doi: 10.1126/science.1118642

Achard, P., Renou, J. P., Berthome, R., Harberd, N. P., and Genschik, P. (2008). Plant DELLAs restrain growth and promote survival of adversity by reducing the levels of reactive oxygen species. Curr. Biol. 18, 656-660. doi: $10.1016 /$ j.cub.2008.04.034

Apel, K., and Hirt, H. (2004). Reactive oxygen species: metabolism, oxidative stress, and signal transduction. Annu. Rev. Plant Biol. 55, 373-399. doi: 10.1146/annurev.arplant.55.031903.141701

Bates, L. S., Waldren, R. P., and Teare, I. D. (1973). Rapid determination of free proline for water-stress studies. Plant Soil 39, 205-207. doi: $10.1007 /$ BF00018060

Chen, Z., Cuin, T. A., Zhou, M., Twomey, A., Naidu, B. P., and Shiabala, S. (2007). Compatible solute accumulation and stress-mitigating effects in barley genotypes contrasting in their salt tolerance. J. Exp. Bot. 58, 4245-4255. doi: $10.1093 /$ jxb/erm284

Colebrook, E. H., Thomas, S. G., Phillips, A. L., and Hedden, P. (2014). The role of gibberellin signalling in plant responses to abiotic stress. J. Exp. Biol. 217, 67-75. doi: 10.1242/jeb.089938

Czikkel, B. E., and Maxwell, D. P. (2007). NtGRAS1, a novel stress-induced member of the GRAS family in tobacco, localizes to the nucleus. J. Plant Physiol. 164, 1220-1230. doi: 10.1016/j.jplph.2006.07.010

Dat, J., Vandenabeele, S., Vranova, E., Van Montagu, M., Inze, D., and Van Breusegem, F. (2000). Dual action of the active oxygen species during plant stress responses. Cell. Mol. Life Sci. 57, 779-795. doi: 10.1007/s000180050041

Della, R. F., Fattorini, L., D’Angeli, S., Veloccia, A., Del, D. S., Cai, G., et al. (2015). Arabidopsis SHR and SCR transcription factors and AUX1 auxin influx carrier control the switch between adventitious rooting and xylogenesis in planta and in in vitro cultured thin cell layers. Ann. Bot. 115, 617-628. doi: $10.1093 / \mathrm{aob} / \mathrm{mcu} 258$

Distefano, G., La Malfa, S., Vitale, A., Lorito, M., Deng, Z. N., and Gentile, A. (2008). Defence-related gene expression in transgenic lemon plants producing an antimicrobial Trichoderma harzianum endochitinase during fungal infection. Transgenic Res. 17, 873-879. doi: 10.1007/s11248-008-9172-9

Farooq, M., Wahid, A., Lee, D. J., Ito, O., and Siddique, K. H. M. (2009). Advances in drought resistance of rice. Crit. Rev. Plant Sci. 28, 199-217. doi: 10.1080/07352680902952173

Fillatti, J. A. J., Kiser, J., Rose, R., and Comai, L. (1987). Efficient transfer of a glyphosate tolerance gene into tomato using a binary Agrobacterium Tumefaciens vector. Nat. Biotechnol. 5, 726-730. doi: 10.1038/nbt0787-726 data; YL and WH wrote the manuscript; ZL and ZX revised the manuscript.

\section{FUNDING}

This work was supported by the National Key Research and Development Program of China (No. 2016YFD0400101), the National Basic Research Program of China (No. 2013CB127101), and the National Natural Science Foundation of China (No. 31272166, 31401924).

\section{SUPPLEMENTARY MATERIAL}

The Supplementary Material for this article can be found online at: http://journal.frontiersin.org/article/10.3389/fpls.2017. 01659/full\#supplementary-material

Foyer, C. H., and Noctor, G. (2005). Oxidant and antioxidant signalling in plants: a re-evaluation of the concept of oxidative stress in a physiological context. Plant Cell Environ. 28, 1056-1071. doi: 10.1111/j.1365-3040.2005.01327.x

Fu, X., and Harberd, N. P. (2003). Auxin promotes Arabidopsis root growth by modulating gibberellin response. Nature 421, 740-743. doi: 10.1038/nature 01387

Fukao, T., Xu, K. N., Ronald, P. C., and Bailey-Serres, J. (2006). A variable cluster of ethylene response factor-like genes regulates metabolic and developmental acclimation responses to submergence in rice(W). Plant Cell 18, 2021-2034. doi: 10.1105/tpc.106.043000

Gao, M. J., Parkin, I. A. P., Lydiate, D. J., and Hannoufa, A. (2004). An auxinresponsive SCARECROW-like transcriptional activator interacts with histone deacetylase. Plant Mol. Biol. 55, 417-431. doi: 10.1007/s11103-004-0892-9

Gillaspy, G., Ben-David, H., and Gruissem, W. (1993). Fruits: a developmental perspective. Plant Cell 5, 1439-1451. doi: 10.1105/tpc.5.10.1439

Heath, R. L., and Packer, L. (1968). Photoperoxidation in isolated chloroplasts.I. Kinetics and stoichiometry of fatty acid peroxidation. Arch. Biochem. Biophys. 125, 189-198. doi: 10.1016/0003-9861(68)90654-1

Heo, J. O., Chang, K. S., Kim, I. A., Lee, M. H., Lee, S. A., Song, S. K., et al. (2011). Funneling of gibberellin signaling by the GRAS transcription regulator SCARECROW-LIKE 3 in the Arabidopsis root. Proc. Natl. Acad. Sci. U.S.A. 108, 2166-2171. doi: 10.1073/pnas.1012215108

Hirayama, T., and Shinozaki, K. (2010). Research on plant abiotic stress responses in the post-genome era: past, present and future. Plant J. 61, 1041-1052. doi: 10.1111/j.1365-313X.2010.04124.x

Huang, W., Peng, S., Xian, Z., Lin, D., Hu, G., Yang, L., et al. (2017). Overexpression of a tomato miR171 target gene SlGRAS24 impacts multiple agronomical traits via regulating gibberellin and auxin homeostasis. Plant Biotechnol. J. 15, 472-488. doi: 10.1111/pbi.12646

Huang, W., Xian, Z., Hu, G., and Li, Z. (2016). SlAGO4A, a core factor of RNA-directed DNA methylation (RdDM) pathway, plays an important role under salt and drought stress in tomato. Mol. Breed. 36:28. doi: 10.1007/s11032-016-0439-1

Huang, W., Xian, Z., Kang, X., Tang, N., and Li, Z. (2015). Genome-wide identification, phylogeny and expression analysis of GRAS gene family in tomato. BMC Plant Biol. 15:209. doi: 10.1186/s12870-015-0590-6

Jain, M., and Khurana, J. P. (2009). Transcript profiling reveals diverse roles of auxin-responsive genes during reproductive development and abiotic stress in rice. FEBS J. 276, 3148-3162. doi: 10.1111/j.1742-4658.2009.07033.x

Kai, X., Chen, S., Li, T., Ma, X., Liang, X., Ding, X., et al. (2015). OsGRAS23, a rice GRAS transcription factor gene, is involved in drought stress response through regulating expression of stress-responsive genes. BMC Plant Biol. 15:141. doi: 10.1186/s12870-015-0532-3 
Kaplan, F., Sung, D. Y., and Guy, C. L. (2006). Roles of beta-amylase and starch breakdown during temperatures stress. Physiol. Plant. 126, 120-128. doi: 10.1111/j.1399-3054.2006.00604.x

Lee, H., Kim, B., Song, S. K., Heo, J. O., Yu, N. I., Lee, S. A., et al. (2008). Large-scale analysis of the GRAS gene family in Arabidopsis thaliana. Plant Mol. Biol. 67, 659-670. doi: 10.1007/s11103-008-9345-1

Lee, S., Cheng, H., King, K. E., Wang, W., He, Y., Hussain, A., et al. (2002). Gibberellin regulates Arabidopsis seed germination via RGL2, a GAI/RGA-like gene whose expression is up-regulated following imbibition. Gene Dev. 16, 646-658. doi: 10.1101/gad.969002

Li, X. Y., Qian, Q., Fu, Z. M., Wang, Y. H., Xiong, G. S., Zeng, D. L., et al. (2003). Control of tillering in rice. Nature 422, 618-621. doi: 10.1038/nature 01518

Lu, C. W., Li, Y. C., Chen, A. J., Li, L., Zuo, J. H., Tian, H. Q., et al. (2010). LeERF1 improves tolerance to drought stress in tomato (Lycopersicon esculentum) and activates downstream stress-responsive genes. Afr. J. Biotechnol. 9, 6294-6300.

Ma, H. S., Liang, D., Shuai, P., Xia, X. L., and Yin, W. L. (2010). The salt- and drought-inducible poplar GRAS protein SCL7 confers salt and drought tolerance in Arabidopsis thaliana. J. Exp. Bot. 61, 4011-4019. doi: $10.1093 / \mathrm{jxb} / \mathrm{erq} 217$

Mahanil, S., Attajarusit, J., Stout, M. J., and Thipyapong, P. (2008). Overexpression of tomato polyphenol oxidase increases resistance to common cutworm. Plant Sci. 174, 456-466. doi: 10.1016/j.plantsci.2008.01.006

Mayrose, M., Ekengren, S. K., Melech-Bonfil, S., Martin, G. B., and Sessa, G. (2006). A novel link between tomato GRAS genes, plant disease resistance and mechanical stress response. Mol. Plant Pathol. 7, 593-604. doi: 10.1111/j.1364-3703.2006.00364.x

Mittova, V., Volokita, M., Guy, M., and Tal, M. (2000). Activities of SOD and the ascorbate-glutathione cycle enzymes in subcellular compartments in leaves and roots of the cultivated tomato and its wild salt-tolerant relative Lycopersicon pennellii. Physiol. Plant. 110, 42-51. doi: 10.1034/j.1399-3054.2000. 110106.x

Morohashi, K., Minami, M., Takase, H., Hotta, Y., and Hiratsuka, K. (2003). Isolation and characterization of a novel GRAS gene that regulates meiosis-associated gene expression. J. Biol. Chem. 278, 20865-20873. doi: 10.1074/jbc.M301712200

Morohashi, Y. (2002). Peroxidase activity develops in the micropylar endosperm of tomato seeds prior to radicle protrusion. J. Exp. Bot. 53, 1643-1650. doi: $10.1093 / \mathrm{jxb} / \mathrm{erf012}$

Pan, Y., Seymour, G. B., Lu, C. G., Hu, Z. L., Chen, X. Q., and Chen, G. P. (2012). An ethylene response factor (ERF5) promoting adaptation to drought and salt tolerance in tomato. Plant Cell Rep. 31, 349-360. doi: 10.1007/s00299-011-1170-3

Paponov, I. A., Paponov, M., Teale, W., Menges, M., Chakrabortee, S., Murray, J. A., et al. (2008). Comprehensive transcriptome analysis of auxin responses in Arabidopsis. Mol. Plant 1, 321-337. doi: 10.1093/mp/ssm021

Peng, J. R., Carol, P., Richards, D. E., King, K. E., Cowling, R. J., Murphy, G. P., et al. (1997). The Arabidopsis GAI gene defines a signaling pathway that negatively regulates gibberellin responses. Gene Dev 11, 3194-3205. doi: 10.1101/gad.11.23.3194

Sanchez, C., Vielba, J. M., Ferro, E., Covelo, G., Sole, A., Abarca, D., et al. (2007). Two SCARECROW-LIKE genes are induced in response to exogenous auxin in rooting-competent cuttings of distantly related forest species. Tree Physiol. 27, 1459-1470. doi: 10.1093/treephys/27. 10.1459

Seki, M., Narusaka, M., Ishida, J., Nanjo, T., Fujita, M., Oono, Y., et al. (2002). Monitoring the expression profiles of 7000 Arabidopsis genes under drought, cold and high-salinity stresses using a full-length cDNA microarray. Plant J. 31, 279-292. doi: 10.1046/j.1365-313X.2002.01359.x

Serrani, J. C., Fos, M., Atares, A., and Garcia-Martinez, J. L. (2007a). Effect of gibberellin and auxin on parthenocarpic fruit growth induction in the cv micro-tom of tomato. J. Plant Growth Regul. 26, 211-221. doi: $10.1007 / \mathrm{s} 00344-007-9014-7$
Serrani, J. C., Sanjuan, R., Ruiz-Rivero, O., Fos, M., and Garcia-Martinez, J. L. (2007b). Gibberellin regulation of fruit set and growth in tomato. Plant Physiol 145, 246-257. doi: 10.1104/pp.107.098335

Silverstone, A. L., Ciampaglio, C. N., and Sun, T. P. (1998). The Arabidopsis $R G A$ gene encodes a transcriptional regulator repressing the gibberellin signal transduction pathway. Plant Cell 10, 155-169. doi: 10.1105/tpc.10.2.155

Singh, K. B., Foley, R. C., and Onate-Sanchez, L. (2002). Transcription factors in plant defense and stress responses. Curr. Opin. Plant Biol. 5, 430-436. doi: $10.1016 /$ S1369-5266(02)00289-3

Torres-Galea, P., Huang, L. F., Chua, N. H., and Bolle, C. (2006). The GRAS protein SCL13 is a positive regulator of phytochrome-dependent red light signaling, but can also modulate phytochrome A responses. Mol. Genet. Genomics 276, 13-30. doi: 10.1007/s00438-006-0123-y

Tyburski, J., Dunajska, K., Mazurek, P., Piotrowska, B., and Tretyn, A. (2009). Exogenous auxin regulates $\mathrm{H}_{2} \mathrm{O}_{2}$ metabolism in roots of tomato (Lycopersicon esculentum Mill.) seedlings affecting the expression and activity of CuZnsuperoxide dismutase, catalase, and peroxidase. Acta Physiol. Plant 31, 249-260. doi: 10.1007/s11738-008-0225-8

Vendruscolo, E. C., Schuster, I., Pileggi, M., Scapim, C. A., Molinari, H. B., Marur, C. J., et al. (2007). Stress-induced synthesis of proline confers tolerance to water deficit in transgenic wheat. J. Plant Physiol. 164, 1367-1376. doi: 10.1016/j.jplph.2007.05.001

Wang, H., Jones, B., Li, Z. G., Frasse, P., Delalande, C., Regad, F., et al. (2005). The tomato Aux/IAA transcription factor IAA9 is involved in fruit development and leaf morphogenesis. Plant Cell 17, 2676-2692. doi: 10.1105/tpc.105.033415

Yuan, Y. Y., Fang, L. C., Karungo, S. K., Zhang, L. L., Gao, Y. Y., Li, S. H., et al. (2016). Overexpression of VaPAT1, a GRAS transcription factor from Vitis amurensis, confers abiotic stress tolerance in Arabidopsis. Plant Cell Rep. 35, 655-666. doi: 10.1007/s00299-015-1910-x

Zhang, C. J., Liu, J. X., Zhang, Y. Y., Cai, X. F., Gong, P. J., Zhang, J. H., et al. (2011). Overexpression of SlGMEs leads to ascorbate accumulation with enhanced oxidative stress, cold, and salt tolerance in tomato. Plant Cell Rep. 30, 389-398. doi: 10.1007/s00299-010-0939-0

Zhang, Q., Li, J. J., Zhang, W. J., Yan, S. N., Wang, R., Zhao, J. F., et al. (2012). The putative auxin efflux carrier OsPIN3t is involved in the drought stress response and drought tolerance. Plant J. 72, 805-816. doi: 10.1111/j.1365-313X.2012.05121.x

Zhang, S. W., Li, C. H., Cao, J., Zhang, Y. C., Zhang, S. Q., Xia, Y. F., et al. (2009). Altered architecture and enhanced drought tolerance in rice via the downregulation of indole-3-acetic acid by TLD1/OsGH3.13 activation. Plant Physiol. 151, 1889-1901. doi: 10.1104/pp.109.146803

Zhang, Z. L., Ogawa, M., Fleet, C. M., Zentella, R., Hu, J. H., Heo, J. O., et al. (2011). SCARECROW-LIKE 3 promotes gibberellin signaling by antagonizing master growth repressor DELLA in Arabidopsis. Proc. Natl. Acad. Sci. U.S.A. 108, 2160-2165. doi: 10.1073/pnas. 1012232108

Zhang, Z. Q., Wang, Y. F., Chang, L. Q., Zhang, T., An, J., Liu, Y. S., et al. (2016). $M s Z E P$, a novel zeaxanthin epoxidase gene from alfalfa (Medicago sativa), confers drought and salt tolerance in transgenic tobacco. Plant Cell Rep. 35, 439-453. doi: 10.1007/s00299-015-1895-5

Zhu, J. K. (2002). Salt and drought stress signal transduction in plants. Annu. Rev. Plant Biol. 53, 247-273. doi: 10.1146/annurev.arplant.53.091401.143329

Conflict of Interest Statement: The authors declare that the research was conducted in the absence of any commercial or financial relationships that could be construed as a potential conflict of interest.

Copyright (๑ 2017 Liu, Huang, Xian, Hu, Lin, Ren, Chen, Su and Li. This is an open-access article distributed under the terms of the Creative Commons Attribution License (CC BY). The use, distribution or reproduction in other forums is permitted, provided the original author(s) or licensor are credited and that the original publication in this journal is cited, in accordance with accepted academic practice. No use, distribution or reproduction is permitted which does not comply with these terms. 